\title{
A regional real-time forecast of marine boundary layers during VOCALS-REx
}

\author{
S. Wang ${ }^{1}$, L. W. O'Neill ${ }^{2}$, Q. Jiang ${ }^{1}$, S. P. de Szoeke ${ }^{3}$, X. Hong ${ }^{1}$, H. Jin ${ }^{1}$, W. T. Thompson ${ }^{1}$, and X. Zheng ${ }^{4}$ \\ ${ }^{1}$ Naval Research Laboratory, Monterey, CA, USA \\ ${ }^{2}$ National Research Council, Naval Research Laboratory, Monterey, CA, USA \\ ${ }^{3}$ Oregon State University, College of Ocean and Atmospheric Sciences, Corvallis, Oregon, USA \\ ${ }^{4}$ RSMA, University of Miami, Miami, FL, USA
}

Received: 7 July 2010 - Published in Atmos. Chem. Phys. Discuss.: 4 August 2010

Revised: 17 November 2010 - Accepted: 28 December 2010 - Published: 17 January 2011

\begin{abstract}
This paper presents an evaluation and validation of the Naval Research Laboratory's COAMPS ${ }^{\circledR}$ real-time forecasts during the VOCALS-REx over the area off the west coast of Chile/Peru in the Southeast Pacific during October and November 2008. The analyses focus on the marine boundary layer (MBL) structure. These forecasts are compared with lower troposphere soundings, in situ surface measurements, and satellite observations. The predicted mean MBL cloud and surface wind spatial distributions are in good agreement with the satellite observations. The large-scale longitudinal variation of the MBL structure along $20^{\circ} \mathrm{S}$ is captured by the forecasts. That is, the MBL height increases westward toward the open ocean, the moisture just above the inversion decreases, and the MBL structure becomes more decoupled offshore. The observed strong wind shear across the cloud-top inversion near $20^{\circ} \mathrm{S}$ was correctly predicted by the model. The model's cloud spatial and temporal distribution in the $15 \mathrm{~km}$ grid mesh is sporadic compared to satellite observations. Our results suggest that this is caused by gridscale convection likely due to a lack of a shallow cumulus convection parameterization in the model. Both observations and model forecasts show wind speed maxima near the top of MBL along $20^{\circ} \mathrm{S}$, which is consistent with the westward upslope of the MBL heights based on the thermal wind relationship. The forecasts produced well-defined diurnal variations in the spatially-averaged MBL structure, although the overall signal is weaker than those derived from the in situ measurements and satellite data. The MBL heights are gen-
\end{abstract}

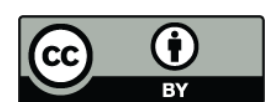

Correspondence to: S. Wang (shouping.wang@nrlmry.navy.mil) erally underpredicted in the nearshore area. An analysis of the sensitivity of the MBL height to horizontal and vertical grid resolution suggests that the underprediction is likely associated with overprediction of the mesoscale downward motion and cold advection near the coast.

\section{Introduction}

The marine boundary layer is known to play key roles in regulating large- and meso-scale atmospheric circulations as it serves as the major source of moist available energy for atmospheric circulation and the major sink of atmospheric kinetic energy (e.g., Lorenz, 1978; Palmen and Newton, 1969). Clouds are frequently present within the MBL in the form of overcast stratocumulus/stratus, organized scattered shallow cumulus clouds or transitional mixture of both; they cover a third of the world's oceans and form a persistent feature of the Earth's climate and regional weather (Klein and Hartmann, 1993; Felsch and Whitlatch, 1993). These clouds have a significant influence on the underlying surface energy budget by significantly reflecting incoming solar energy, but only moderately increasing downward longwave radiative flux (Klein and Hartmann, 1993). In addition, the cloudtop radiative cooling created by the clouds and the latent heat released by convective updrafts fundamentally change the nature of the turbulence dynamics compared to a cloud-free MBL, leading to changes in thermodynamic and wind profiles in the MBL (Lilly, 1968). Consequently, air-sea interaction processes are profoundly impacted by the presence of these clouds at both global and regional scales. It is of great importance, therefore, that coupled climate and mesoscale

Published by Copernicus Publications on behalf of the European Geosciences Union. 
models are able to realistically predict the MBL structure, cloud coverage and their variability (Ma et al., 1996; Bony and Dufresne, 2005; de Szoeke et al., 2006, and Shulman et al., 2007).

The cloud-topped MBL is, however, notoriously difficult to simulate, because turbulence-cloud interaction processes cannot be explicitly resolved at current grid resolutions of global and regional models and thus must be parameterized. For example, an interactive turbulence-shallow convection parameterization is essential to predict the transition from stratocumulus to shallow cumulus clouds (Park and Bretherton, 2009). Furthermore, mesoscale cloud variability may also be driven by the so-called aerosol-cloud-precipitation interaction mechanism proposed by Albrecht (1989), in which low CCN (Cloud Condensation Nuclei) concentration promotes more precipitation, leading to the destruction and structural change of the clouds (e.g., Stevens et al., 2005; Wang and Feingold, 2009). The representation of this complex interaction process has not yet been developed for use in regional and global models.

Two primary focuses of VOCALS-REx (Variability of the American Monsoons Ocean-Cloud-Atmosphere-Land Study-Regional experiment) are: (1) the aerosol-cloudprecipitation interaction in the MBL; and (2) chemical and physical couplings between the upper ocean, the land, and the atmosphere (Wood et al., 2010). The field campaign took place off the west coast of Chile/Peru in the Southeast Pacific during October and November 2008. Comprehensive measurements were made on many platforms including aircrafts, ships, satellites, buoys, and land-based observation sites to provide description of the MBL structure, turbulence dynamics, aerosol-cloud microphysics and air-sea interaction. Particularly, intensive observations were carried out along the latitude $20^{\circ} \mathrm{S}$ to provide detailed time-height and longitudeheight cross-sections of the MBL.

One important motivation for VOCALS-REx is to improve the prediction of MBL clouds by both global and regional models. Because of the prominent impacts of MBL clouds on global climate as discussed earlier, modeling efforts have traditionally emphasized global models. In the last few decades, however, an increasing number of studies have focused on the regional modeling investigations of MBL clouds, including regional simulations using a simple two-layer model (Wang et al., 1993), cloud evaluation and process studies using mesoscale models in a regional climate mode (e.g., Wang et al., 2004a, b; McCaa and Bretherton, 2004; Garreaud and Muñoz, 2004), investigations of cloud and dynamic processes in case studies (Mocko and Cotton, 1995; Mechem and Kogan, 2003; Thompson et al., 2005), and study of shallow cumulus effects in regional ocean-atmosphere coupled climate model (de Szoeke et al., 2006). These regional model studies demonstrate that the fidelity of the MBL cloud simulations is highly dependent on the quality of the cloud and turbulence parameterizations as well as the accuracy of the large- and mesoscale flows. A recent assessment of current global and regional models clearly shows weakness in the simulated cloudiness and MBL heights, two important parameters in the MBL cloud prediction (Wyant et al., 2010).

During October-November 2008, NRL's (Naval Research Laboratory's) COAMPS (Coupled Ocean/Atmosphere Mesoscale Prediction System) real-time forecasts were performed in support of VOCALS-REx. The current work presented here focuses on evaluation and validation of these MBL forecasts using observations taken during the VOCALS-REx field program. It is motivated by the following questions: to what degree do the predicted cloud fields such as integrated cloud water path agree with observations? To what degree does the predicted MBL structure agree with that observed? What specific aspects of the model can be improved to better simulate the MBL cloud system?

Section 2 describes COAMPS, the forecast setup, and the observational datasets. Sections 3-6 analyze COAMPS regional fields, MBL variations along $20^{\circ} \mathrm{S}$, statistics of the surface variables, and mean MBL diurnal structure. Section 7 discusses the issue of the model grid resolution and Sect. 8 gives the summary and conclusion.

\section{COAMPS real-time forecast setup and observation datasets}

The atmospheric component of COAMPS represents both a forecast model and a complete three-dimensional data assimilation system. The forecast model is a finite-difference approximation to the fully incompressible and non-hydrostatic equations that govern atmospheric motions (Hodur, 1997). The main model physical representations relevant to this study are briefly described as follows. For the boundary layer prediction, the surface layer is represented using the modified version of the Louis (1982) surface flux parameterization as formulated by Wang et al. (2002); turbulence mixing processes are parameterized following the MellorYamada's 1.5 order turbulence closure model that predicts turbulence kinetic energy and determines the turbulent fluxes in terms of the down-gradient transport approach (Mellor and Yamada, 1982). To account for latent heat effect of clouds on the buoyancy in turbulence mixing, the subgridscale cloud fraction is calculated using a Gaussian distribution of turbulent fluctuations of conserved variables (Burk and Thompson, 1989). However, the cloud fraction is not used in the radiation calculation. The cumulus parameterization of Kain and Fritsch (1990) is used to represent the convection at the subgrid scale; and it is only activated when the grid size is greater than $10 \mathrm{~km}$. The current version of this convection scheme, however, is not designed to represent shallow cumulus clouds, which is a limitation that will be discussed further in Sect. 4. Clouds and precipitation at grid scale are predicted using the single moment scheme of cloud microphysics formulated by Rutledge and Hobbs (1983). Recently, the four-stream radiation parameterization of $\mathrm{Fu}$ 
and Liou (1992) was implemented in COAMPS (Liu et al., 2009).

The initialization of COAMPS forecasts is performed by a data assimilation system that uses multivariate optimum interpolation analyses of soundings, surface and satellite data and blended with the previous 12-h COAMPS forecast fields. Lateral boundary conditions for the outermost domain are provided by the Navy Operational Global Analysis and Prediction System (NOGAPS) forecast fields. The sea surface temperature (SST) is generated by the NRL Coupled Ocean Data Assimilation System (NCODA), which applies a threedimensional, multivariate, optimum-interpolation method and integrates all available ocean observations in real time, including ship, buoy, and satellite observations as discussed in Cummings (2005).

During VOCALS-REx, COAMPS provided $48 \mathrm{~h}$ twicedaily forecasts with a 3-h interval output, initialized at 00:00 UTC and 12:00 UTC, between 20 October and 29 November 2008. As shown in Fig. 1, the forecast domain is configured to contain three nested grid meshes $(45 \mathrm{~km}$, $15 \mathrm{~km}$, and $5 \mathrm{~km}$ ) with 45 levels in the vertical, of which 26 levels reside below $2.5 \mathrm{~km}$. Our analysis is focused on the forecast from the $15 \mathrm{~km}$ domain, as the $15 \mathrm{~km}$ grid mesh covers most of the VOCALS-REx observation areas and has a relatively high horizontal resolution. Some results from the $45 \mathrm{~km}$ and $5 \mathrm{~km}$ grid meshes will also be presented to provide comparisons in Sect. 2 (Fig. 2) and Sect. 7 (Figs. 15 and 16).

The observational data employed in this study include both satellite observations and in-situ measurements made during VOCALS-REx. Satellite observations of liquid water path (LWP) and surface wind speed are from 4 passive microwave radiometers onboard the AMSR-E (Advanced Microwave Scanning Radiometer - Earth Observing System), TRMM (Tropical Rainfall Measuring Mission) Microwave Imager (TMI), and the SSM/I (Special Sensor Microwave Imager) F13 and F15 satellites. SST fields from the AMSR$\mathrm{E}$ and TMI satellites were used as an independent evaluation of the NCODA SST fields used as the lower boundary condition in these COAMPS forecasts. Additionally, vector surface winds from QuickSCAT (Quick Scatterometer) are also used for comparison. Atmospheric sounding data used in this work were collected on board NOAA R/V Ronald H. Brown (RHB) along $20^{\circ} \mathrm{S}$ and on board CIRPAS (Center for Interdisciplinary Remotely Piloted Aircraft Studies) Twin Otter research flights at the location of $20^{\circ} \mathrm{S}$ and $72^{\circ} \mathrm{W}$. Ship-based surface observations and rawinsondes are available every $10 \mathrm{~min}$ from the multi-year NOAA tropical eastern Pacific synthesis data set (de Szoeke et al., 2010). These surface observations consist of a 10-min synthesis data set from the VOCALS-REx RHB cruise and data collected at the WHOI buoy located at $85^{\circ} \mathrm{W}$ and $20^{\circ} \mathrm{S}$. Readers are referred to Wood et al. (2010) for a complete description of the in situ observations and platforms during VOCALS-REx.

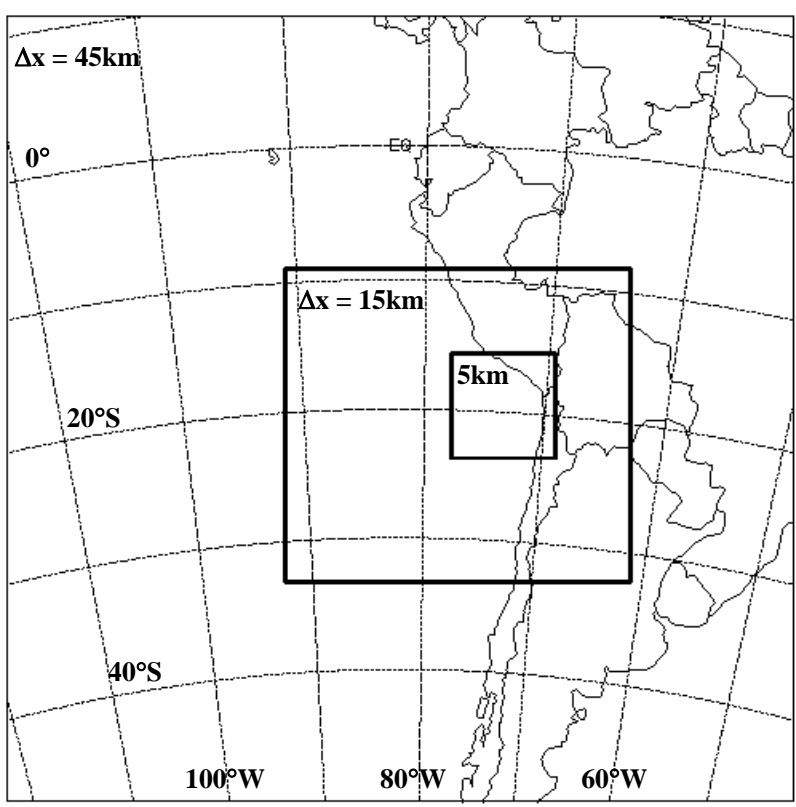

Fig. 1. COAMPS forecast domains for the VOCALS-REx. Three grid meshes $(45 \mathrm{~km}, 15 \mathrm{~km}, 5 \mathrm{~km})$ have $151 \times 151,199 \times 188$, and $151 \times 151$ grid points, respectively.

\section{Regional fields}

In this section, we first examine the mean large-scale features by comparing the COAMPS 41-day (20 October to 29 November) averaged fields on the $45 \mathrm{~km}$ grid mesh with those derived from the satellite data over an expanded area in the Southeast Pacific. We then focus on the mean and diurnal variability of the wind and cloud fields using the models results on the $15 \mathrm{~km}$ grid mesh over the VOCALS-REx area.

As shown in Fig. 2a and b, the model SST accurately captures all the major features shown by the AMSR-E and TMI SST field. Both SST fields are colder close to the Chilean coast, driven by the low-level jet of strong southerly winds parallel to the coast shown in the wind fields between $40^{\circ} \mathrm{S}$ and $25^{\circ} \mathrm{S}$ (Fig. $2 \mathrm{c}$ and d). The locally warm SST area centered at $72^{\circ} \mathrm{W}$ and $20^{\circ} \mathrm{S}$ results from the weak southerly winds blocked by the Andes. A broad region of cold SST (green shaded) is present to the northwest of the coastal upwelling zone; it appears to result from the oceanic cold advection driven by the southeast wind from the low-level jet area to the northern side of the high pressure system. Even though the model SST is a product of the ocean data assimilation system, the AMSR-E and TMI data were not included in NCODA for the ocean analysis. Therefore, this comparison also serves as an independent validation of the NCODA product.

The forecast surface wind vectors agree with the satellite QuickSCAT data in the following main features. The southerly coastal jet along the Chilean coast is consistent 

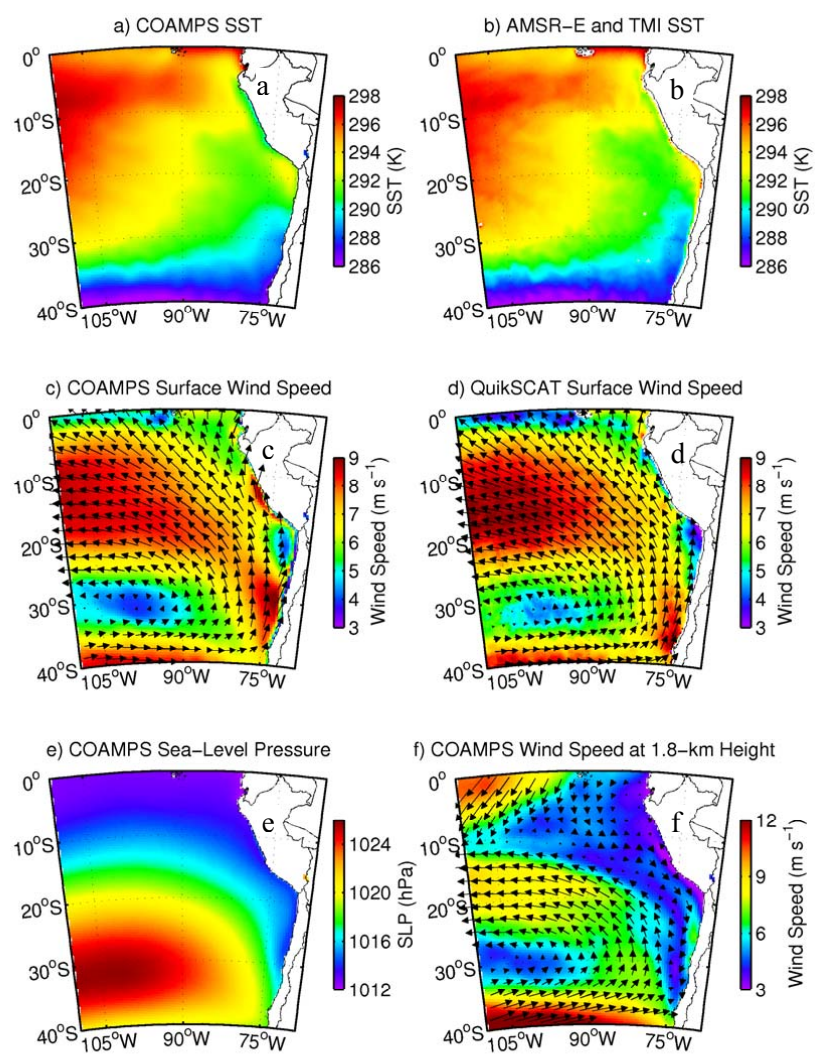

Fig. 2. Mean large-scale fields derived from the COAMPS forecasts (45 km grid) and the satellite data. (a) COAMPS SST; (b) AMSR-E and TMI SST; (c) COAMPS 10-m wind speed (color shading) and vectors; (d) QuickScat wind speed (color shading) and vectors; (e) COAMPS sea-level pressure; and (f) COAMPS $1.8 \mathrm{~km}$ wind speed (color shading) and vectors.

with the satellite winds in the overall correct location and direction of the jet axis, although the simulated jet appears stronger and extend further north. Weak wind speed areas are present near the subtropical high pressure center at $105^{\circ} \mathrm{W}$ and $31^{\circ} \mathrm{S}$ and nearshore at $20^{\circ} \mathrm{S}$; and the relatively high wind speeds exist in the northern side of the high pressure system (Fig. 2e). The Chilean low-level jet often takes place in the austral spring and summer seasons and appears to be associated with the northerly directed pressure gradient force along the coast induced by mid-latitude synoptic conditions (Garreaud and Muñoz, 2005; Muñoz and Garreaud, 2005). A recent study by Jiang et al. (2010) using these COAMPS forecasts shows that the subtropical high pressure system is a major forcing regulating the Chilean low-level jet variability.

As shown in Fig. $2 \mathrm{f}$, the main features of the predicted winds just above the MBL inversion at $1.8 \mathrm{~km}$ height include the anti-cyclonic circulation associated with the subtropical high pressure system and the weak wind speed area between the high pressure system and the coast. In particular, a narrow northerly jet flow extends from $15^{\circ} \mathrm{S}$ to $30^{\circ} \mathrm{S}$ along the coast, contrasting the southerly flow within the MBL
(Fig. 2d) and resulting in a sharp wind shear across the inversion. The existence of the strong wind shear is confirmed by the aircraft observations as will be presented later.

We next examine the cloud and wind fields with a focus on the VOCALS-REx area using the $15 \mathrm{~km}$ grid forecasts. The satellite data used for this comparison are derived from the microwave measurements taken on AMSR-E, SSM/I and TMI satellites, which together have a sampling frequency of 4-8 times daily at each grid point in the domain depending on the detailed sampling characteristics of each satellite.

Figures $3 \mathrm{a}$ and $\mathrm{b}$ show that the general patterns of the mean liquid water path (LWP) fields from the forecast and satellite data are very similar. Both LWP fields are characterized by extensive coverage over the southeast Pacific with relatively thick LWP $\left(\sim 100\right.$ to $\left.120 \mathrm{~g} \mathrm{~m}^{-2}\right)$ covering the western part of the domain and thinner clouds along the coast. The LWP decreases significantly to the south of $25^{\circ} \mathrm{S}$, where subsidence tends to dominate near the center of the high pressure system. The COAMPS underpredicts nearshore clouds, particularly along the coast between $16^{\circ} \mathrm{S}$ and $20^{\circ} \mathrm{S}$ and to the south of $25^{\circ} \mathrm{S}$. This deficiency is likely caused by MBL heights that are too low compared with those observed as discussed in the next sections.

As shown in Fig. 3c-d, surface wind speeds from both the COAMPS simulations and the satellite data indicate a weak wind area near the coast between $25^{\circ} \mathrm{S}$ and $17^{\circ} \mathrm{S}$. Both tend to have maximum values in the low-level jet region off the coast of Chile and to the south of $25^{\circ} \mathrm{S}$, although the maxima from the forecast $\left(\sim 8 \mathrm{~m} \mathrm{~s}^{-1}\right)$ are stronger than those from the satellite observations $\left(\sim 7 \mathrm{~m} \mathrm{~s}^{-1}\right)$. The center of the Southeast Pacific high pressure systems is characterized by weak winds and low LWP values associated with strong subsidence, as shown in both the modeled results and satellite observations. The comparison for the $15 \mathrm{~km}$ mesh is generally consistent with that for the $45 \mathrm{~km}$ mesh.

Diurnal variability in the cloud field is a dominant feature over the southeast Pacific (e.g., Rozendaal et al., 1995; O'Dell et al., 2008; Wood et al., 2009). It is primarily driven by the cloud solar absorption during daytime, which tends to stabilize the MBL and decouple the cloud from the surfacebased subcloud layer (Nicholls, 1984). To examine the statistical behavior of diurnal variation of the clouds, a harmonic regression analysis with the diurnal cycle is performed on both the forecasts and the satellite data (Figs. 4 and 5). Because the sampling rate of the satellite data is about 4-8 times per day, we only focus on the dominant $24 \mathrm{~h}$ diurnal cycle. The amplitude of the LWP diurnal cycle is about half of the mean LWP in both the model and satellite observations, implying the presence of a significant cloud diurnal variability. The diurnal amplitude of the cloud LWP is smaller for the forecasts $\left(\sim 30-50 \mathrm{~g} \mathrm{~m}^{-2}\right)$ than for the satellite $(\sim 40$ $\left.60 \mathrm{~g} \mathrm{~m}^{-2}\right)$. The diurnal signals are noticeably weaker near the Peruvian coast in both the satellite and forecasts, where the amplitudes from both fields are about $10-20 \mathrm{~g} \mathrm{~m}^{-2}$. The satellite LWP diurnal amplitude is relatively smooth with 

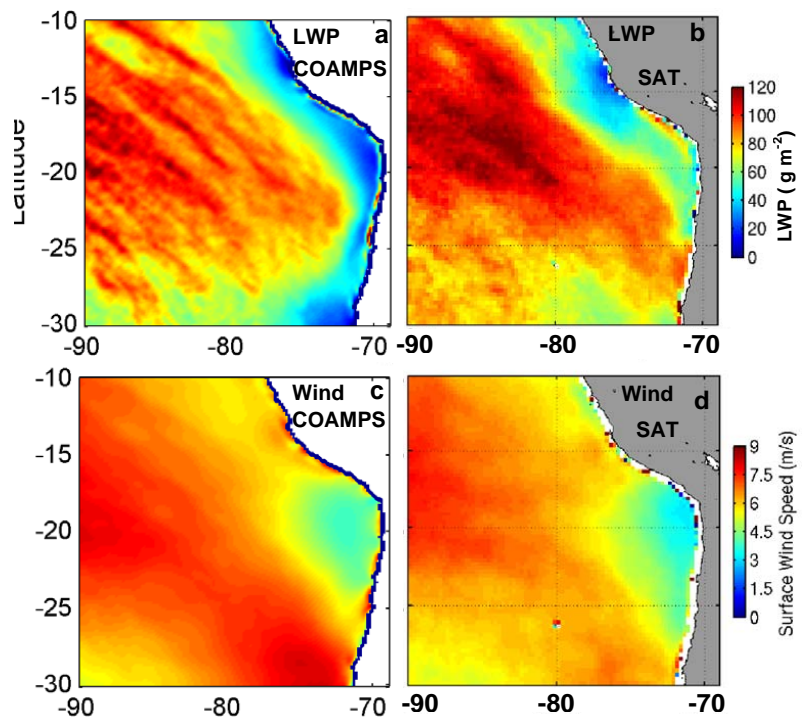

Fig. 3. Comparison of the mean LWP and wind speed between the COAMPS forecasts ( $15 \mathrm{~km}$ grid) and the satellite data. (a) COAMPS LWP; (b) satellite LWP; (c) COAMPS surface wind speed; and (d) satellite wind speed.

the maximum values centered at $81^{\circ} \mathrm{W}$ and $21^{\circ} \mathrm{S}$, while the forecast is rather spotty with high value areas being approximately parallel to wind vectors. Further examination of the instantaneous cloud fields reveals that this discontinuity is likely caused by grid-scale convection and probably due to the lack of shallow cumulus convection parameterization in the model, which will be discussed further in Sect. 4 .

To estimate the diurnal contribution to the total LWP variability, we calculate the correlation of the LWP diurnal harmonic regression with the satellite and the forecasts, respectively. The correlation values for the COAMPS $(\sim 0.3-0.6)$ are smaller than those for the satellite data $(\sim 0.6-0.8)$ over large areas to the west of $72^{\circ} \mathrm{W}$ and the north of $25^{\circ} \mathrm{S}$. These values indicate that while the diurnal cycle can only account for $10-36 \%$ of the total variance in the predicted LWP, it accounts for as high as $36-64 \%$ in the satellite data over these areas. Over the coastal areas near $20^{\circ} \mathrm{S}$, the modeled correlation is about 0.6 , slightly higher than the observation. The phase of the diurnal variation in the forecasts is in general agreement with the satellite data over large region to the east of $85^{\circ} \mathrm{W}$ (Fig. $4 \mathrm{e}$ and $\mathrm{f}$ ), although the timing of the maxima consistently appears $2-4 \mathrm{~h}$ earlier for the model than for the satellite.

Surface wind speeds from both the forecast and the satellite data show diurnal signals over large areas off the Chilean coast reaching as far as $82^{\circ} \mathrm{W}$ as shown in Fig. 5. For the forecast, the area with the largest diurnal amplitude $(\sim 1.2-$ $1.8 \mathrm{~m} \mathrm{~s}^{-1}$ ) appears to be in regions of relatively weak mean wind. The western part of the area overlaps the region of the satellite's large amplitudes centered on $\left(80^{\circ} \mathrm{W}, 26^{\circ} \mathrm{S}\right)$,

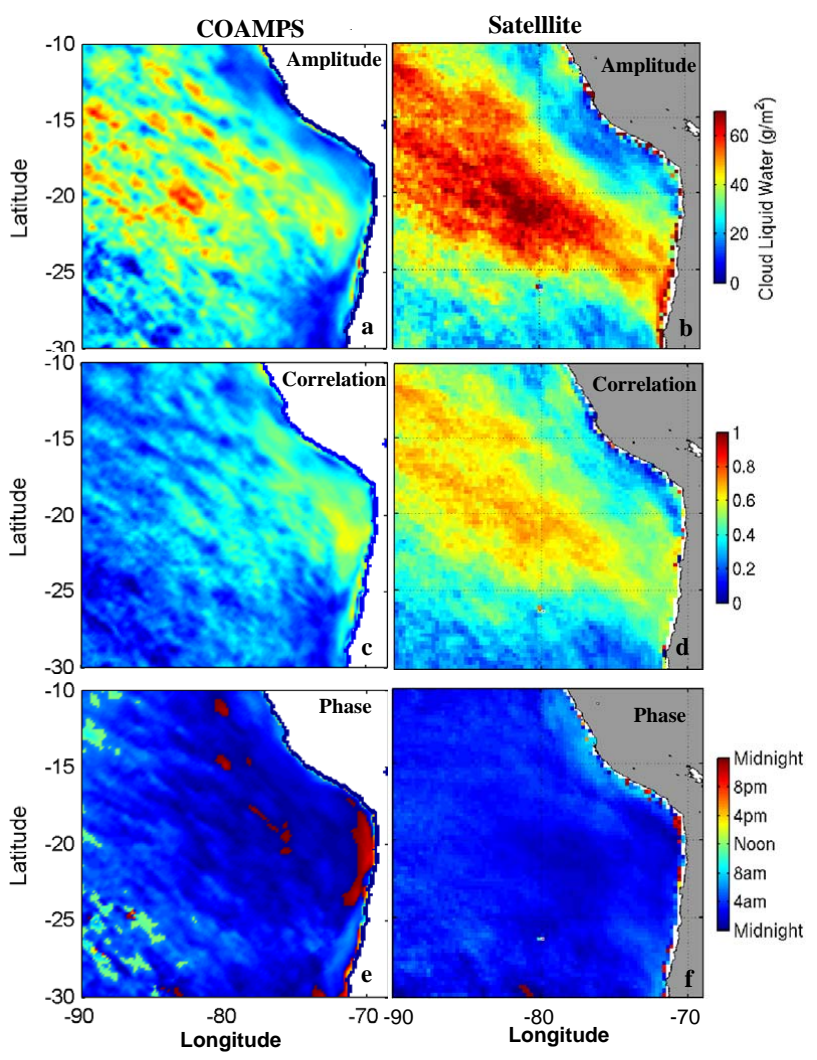

Fig. 4. Comparison of the harmonic analysis of LWP between the COAMPS forecasts (left column) and the satellite data (right column). (a) Predicted diurnal amplitude; (b) satellite diurnal amplitude; (c) correlation with the predicted harmonic diurnal function; (d) correlation with the satellite diurnal function; (e) local hours of the LWP maximum in the model; and (f) local hours of the LWP maximum in the satellite data.

whose values $\left(1.2 \mathrm{~m} \mathrm{~s}^{-1}\right)$ are less than the forecasts. Both the forecasts and the satellite place the large diurnal wind speed amplitude areas to the north and northwest of the low-level jet core offshore of central Chile; it is particularly true for model results. This is consistent with Garreaud and Munoz (2005) who conclude that the diurnal cycle in climatological region of the maximum jet wind speed is small. The correlation pattern of the wind speed and its diurnal variation shows a general agreement between the satellite and the forecasts with larger values covering the coastal area and extending offshore (Fig. 5c and d). For both the COAMPS and satellite wind speed fields, the maximum wind speeds occur in the afternoon along the coast between $25^{\circ} \mathrm{S}$ and $17^{\circ} \mathrm{S}$ (Fig. $5 \mathrm{e}-$ $\mathrm{f}$ ), which is likely produced by the afternoon strengthening of the southerly winds (Rutllant, 1993). For other areas, the wind speeds are maximum during the late evening and early morning. The diurnal variation of the surface wind speed only accounts for $10-25 \%$ of the variances for the satellite as well as the forecast results, a percentage much less than that for the clouds. 


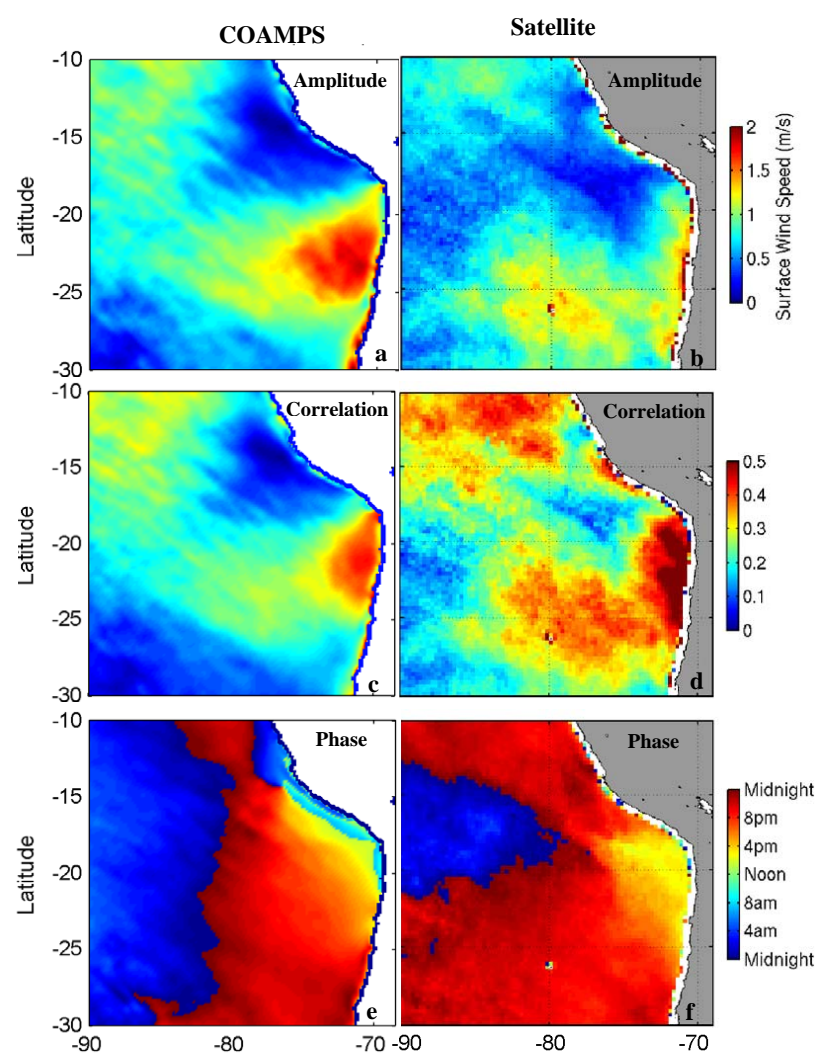

Fig. 5. The same as in Fig. 4 except for the surface wind speed and the correlation coefficient ranges $0-0.5$ now. Note that the scale in the color coding used for the correlation coefficients is different from the corresponding one used in Fig. $3 \mathrm{c}$ and $\mathrm{d}$.

There are some apparent differences between the forecast and satellite wind fields along west coast of Peru. The $45-\mathrm{km}$ grid nest wind speed reaches a local maximum $\left(\sim 9 \mathrm{~m} \mathrm{~s}^{-1}\right)$ compared to only $7 \mathrm{~m} \mathrm{~s}^{-1}$ from the QuickSCAT data (Fig. 2), although the $15-\mathrm{km}$ grid nest forecast compares better with the combined satellite data from AMSR-E, SSM/I and TMI satellites. This may be partly due to the fact that QuikSCAT only has 1-2 passes over a location each day, while the combined dataset has $4-8$ passes. The forecast diurnal amplitude over the area off Chile between $76^{\circ} \mathrm{W}$ and $72^{\circ} \mathrm{W}$ is $\sim 1.25$ $1.75 \mathrm{~m} \mathrm{~s}^{-1}$, significantly larger than that from the satellite data, $\sim 0.5 \mathrm{~m} \mathrm{~s}^{-1}$. Previous multi-year satellite data analyses, however, also show that the morning-to-afternoon wind speed increase can be as large as $1.5 \mathrm{~m} \mathrm{~s}^{-1}$ in the same area (Muñoz, 2008). The diurnal phase difference between the forecast and the satellite is about $12 \mathrm{~h}$ over the $100-\mathrm{km}$ width coastal area off Peru (Fig. 5e and f). The diurnal amplitude along the Peruvian coast is only $0.2-0.5 \mathrm{~ms}^{-1}$, along with a small correlation coefficient about 0.2 , which implies significant uncertainties in the model diurnal statistics. The meridional variation of wind speed phase in this area has been noticed in previous studies. For example, Muñoz (2008) used model simulations to show a decrease in meridional wind speed along the southern coast of Peru from 12:00 to 18:00 LST compared to the corresponding increase over areas off central coast of Chile. Analysis of satellite data also suggest that the timing of the maximum meridional winds off Peru and northern Chile is generally several hours earlier than off the central region of Chile (e.g., Gille et al., 2005). The characteristics of the diurnal variation of surface winds in the coastal area are important, as they reflect the interaction among the lower troposphere circulation, sea breeze and MBL turbulence. Given the high uncertainties regarding the forecast-satellite wind phase difference and the meridional variation of the wind phase shown in these studies, more detailed analyses are needed to produce robust diurnal statistics of both model and observations and investigate the exact nature of the wind diurnal variation.

This regional comparison demonstrates that the predicted mean wind and cloud fields in general agree with the satellite observations, including the low-level jet along the west coast of Chile, the weak wind speed area present near the subtropical high center and in the coastal area near $20^{\circ} \mathrm{S}$, the overall LWP distribution pattern, and diurnal phase pattern for both clouds and wind speeds. The predicted diurnal variance of the LWP from COAMPS explains $10-25 \%$ of the total variance, a percentage smaller than that (30-60\%) derived from the satellite data. Diurnal variation of MBL clouds in the southeast Pacific may also include a 6-h harmonic which is driven by the so-called upsidence wave as discussed by Garreaud and Muñoz (2004) and O'Dell et al. (2008). This variability, however, is not included in the current analysis. It is discussed in detail by Rahn and Garreaud (2010a) using model simulations and observations in VOCALS-REx.

\section{$420^{\circ} \mathrm{S}$ MBL cross-section}

This section focuses on the evaluation of the COAMPS MBL structure on the $15 \mathrm{~km}$ grid mesh along $20^{\circ} \mathrm{S}$ using the RHB rawindsondes, NCAR C-130, and CIRPAS Twin-Otter measurements. The RHB had two cruise legs, with first running from 6 October to 3 November and the second from 11 to 29 November. No data were collected 3-10 November between the two periods while it was stationed in Arica, Chile, and only the data collected along $20^{\circ} \mathrm{S}$ are used here.

Figure 6 compares the time-height cross-section of potential temperature $(\theta)$ vertical profiles of the lower atmosphere from the RHB with those from the forecast. This predicted cross-section is derived using interpolation based on the times and locations of the rawindsondes. The comparison starts at 23:24 UTC 25 October 2008 and ends at 16:00 UTC 28 November 2008, including 196 profiles from each dataset. The observed nearly well-mixed MBL structure capped by a strong inversion is well predicted. The simulated jump in $\theta$ across the inversion appears to be comparable to the observed, although the modeled inversion layer is thicker, 


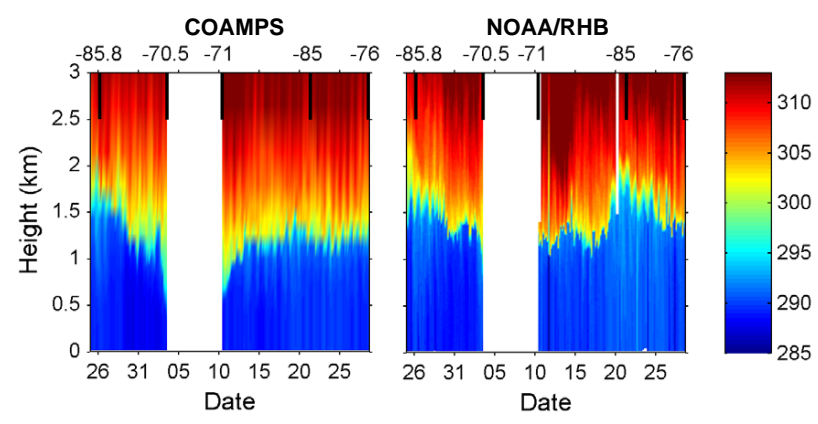

Fig. 6. Time-height cross-section of potential temperature $(\theta)$ from the COAMPS forecasts (left) and the RHB rawindsondes (right). The analysis covers the period of 25 October through 29 November 2008. The numbers at the upper axis with the heavy vertical lines denote the longitudes of the most western and eastern locations of the RHB cruise for each leg during this period. No data were collected 3-10 November between the two cruise legs.

partly due to the limited vertical resolution in the model. For the first 9 days, the variation of the predicted $z_{i}$ closely followed that from the observations except that it lowered to $600 \mathrm{~m}$ while the RHB $z_{i}$ stays above $1 \mathrm{~km}$ near the coast. At the start of leg 2, the modeled $z_{i}$ was again low at $600 \mathrm{~m}$, and then immediately increased to $1.4 \mathrm{~km}$ and varied little afterwards. In contrast, the RHB $z_{i}$ stayed at $\sim 1.3 \mathrm{~km}$ until 18 November, after which time it changed considerably and reached a maximum of $2 \mathrm{~km}$ at $20^{\circ} \mathrm{S}$ and $85^{\circ} \mathrm{W}$. The modeled $z_{i}$ clearly lacks the variability comparable to the RHB observations in leg 2 . The modeled $z_{i}$ is generally lower than in the RHB observations, particularly in the nearshore area.

During VOCALS-REx, two different dominating synoptic conditions are identified (Rahn and Garreaud, 2010b). During October, synoptic disturbances are prominent, strongly modulating $z_{i}$ as demonstrated by both the observations and forecasts as shown by the low frequency variability in the time-height sections of potential temperature in Fig. 6. For this period, the observed variation of $z_{i}$ is very well simulated. In contrast, during November, synoptic forcing is weak over the VOCALS-REx region. For this period, COAMPS appears to have difficulty in predicting correct $z_{i}$ near $20^{\circ} \mathrm{S}$ and $85^{\circ} \mathrm{W}$. A possible explanation for these different model behaviors is as follows. In October, tendency of $z_{i}$ may be dominated by synoptic disturbances which can be resolved by the model. In November without strong synoptic forcing, the tendency may be mostly determined by the turbulence or/and shallow convection which must be parameterized. It is possible that deficiencies in the turbulence parameterization may play more prominant roles, leading to more errors in $z_{i}$ during November. To test this hypothesis, one needs to analyze the budget of $z_{i}$ to compare the relative importance of different processes in the $z_{i}$ budget.
To further examine the MBL vertical structure, we composite the vertical soundings of potential temperature $\theta$, specific humidity $q_{v}$, equivalent potential temperature $\theta_{e}$, and the zonal and meridional wind components ( $u$ and $v$, respectively) according to their distances to the coast. Figure 7 compares the composite soundings centered at 3 locations: "nearshore" $\left(71.64^{\circ} \mathrm{W}, 19.22^{\circ} \mathrm{S}\right)$, "midway" $\left(79.16^{\circ} \mathrm{W}, 19.22^{\circ} \mathrm{S}\right)$, and "offshore" $\left(84.5^{\circ} \mathrm{W}, 20.4^{\circ} \mathrm{S}\right)$. These composites are produced by averaging the soundings within one degree in longitude of the locations. Most of the predicted variables closely follow the observations within the MBL and above the inversions. The well-mixed $\theta$ profiles in the lower MBL are well predicted; the inversion strength also compares well with the observations. There is a clear trend of increasing moisture above the inversion toward the coast in both the forecasts and the RHB observations. A weakness in the predicted MBL structure is the lower $z_{i}$ at both the "nearshore" and "offshore" locations; particularly, $z_{i}$ is underpredicted nearshore by $450 \mathrm{~m}$. It should be mentioned that the 41-day ensemble averaged $z_{i}$ at $85^{\circ} \mathrm{W}$ and $20^{\circ} \mathrm{S}$ is similar to the $\mathrm{C}-130$ soundings, while the low bias of the nearshore $z_{i}$ remains a consistent feature of the forecasts, as shown in next section. The model also produced higher moisture just above the inversion and below $2 \mathrm{~km}$, as shown by the specific humidity $\left(q_{v}\right)$ comparison in Fig. 7 .

The observed equivalent potential temperature $\left(\theta_{e}\right)$ decreases with height below the inversion top (Fig. 7). The negative $\theta_{e}$ gradient becomes stronger toward the open ocean, suggesting that the MBL tends to be more conditionally unstable offshore, a condition favorable for shallow cumulus development (Stevens, 2007). The model prediction of $\theta_{e}$ has a similar feature for the "offshore" and "nearshore" locations. Due to the higher values of $q_{v}$ just above the inversion, the overall change in the modeled $\theta_{e}$ across the MBL is positive at the "midway" location, in contrast to the RHB soundings.

Both the model and the RHB observations show wind maxima just below the inversion with diminishing values upward (Fig. 7). The low wind speed above the MBL is associated with the shallowness typical of subtropical high pressure systems. The meridional wind shear across the inversion is consistent with the zonal temperature gradient within the inversion, introduced by the east-west upward slope of the MBL height along $20^{\circ} \mathrm{S}$. We can estimate the jump in $v$ across the inversion based on the thermal wind relationship using both the model and RHB soundings. First, $\theta$ should remain the same along the inversion slope. That is,

$(d \theta)_{z_{i}}=\left(\frac{\partial \theta}{\partial x}\right)_{z_{i}} d x+\left(\frac{\partial \theta}{\partial z}\right)_{z_{i}} d z_{i}(x)=0$.

Using Eq. (1) and the model soundings, the mean zonal temperature gradient within the inversion can be approximated as, 

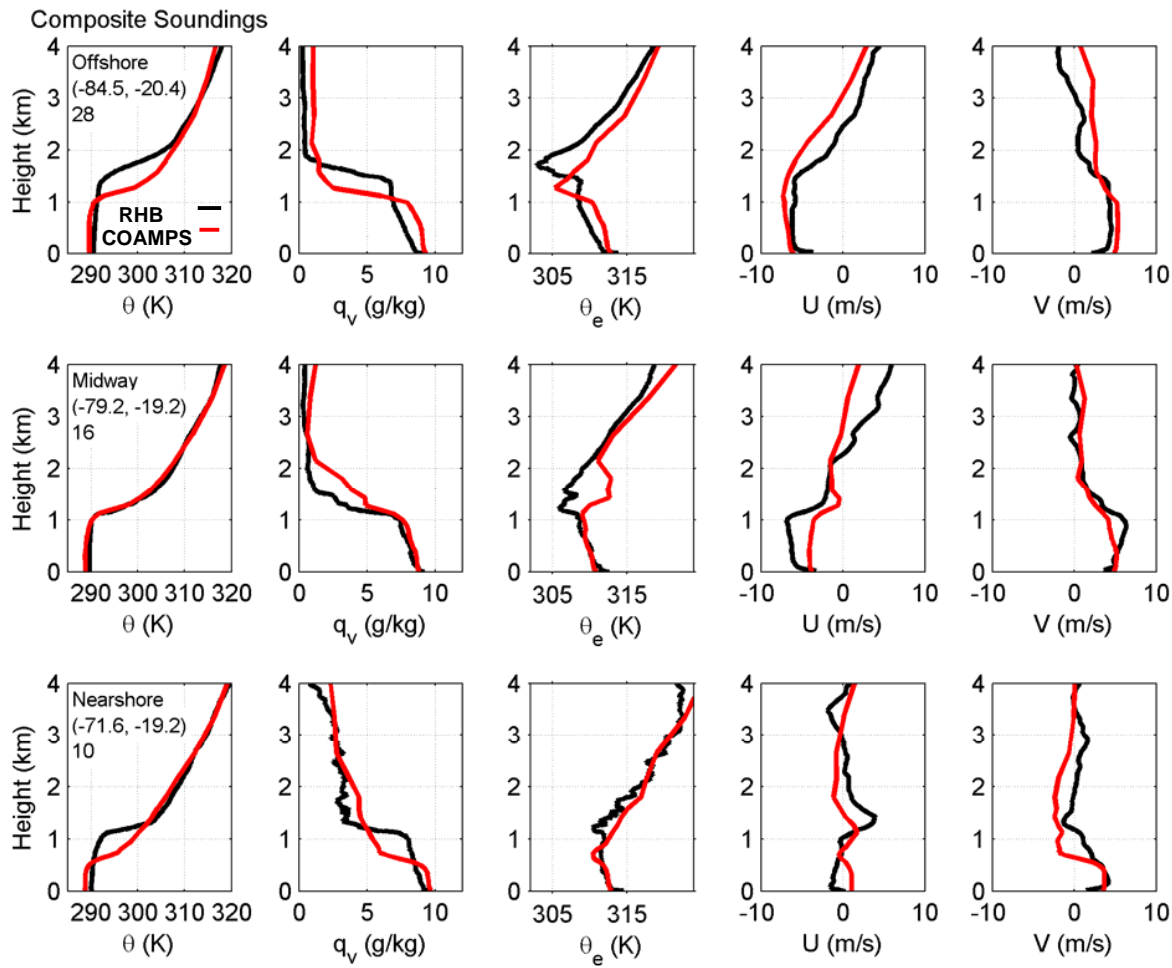

Fig. 7. Comparison of the composite COAMPS and RHB soundings. The soundings are averaged at the central location indicated by the pair of longitude and latitude in the first columns in the figure. The digits under the locations are the total number of soundings used in each averaging. The variables are denoted by $x$-axis labels. Red curves denote the forecast results; and the black the RHB.

$$
\begin{aligned}
\left(\frac{\partial \theta}{\partial x}\right)_{z_{i}} & =-\left(\frac{\partial \theta}{\partial z}\right)_{z_{i}} \cdot \frac{d z_{i}}{d x} \\
& \sim \frac{10 \mathrm{~K}}{400 \mathrm{~m}} \cdot \frac{600 \mathrm{~m}}{1300 \times 10^{3} \mathrm{~m}} \approx 1.2 \times 10^{-5} \mathrm{~K} \mathrm{~m}^{-1}
\end{aligned}
$$

This horizontal temperature gradient gives an estimate of the mean jump in $v$ using the thermal wind relationship:

$$
\begin{gathered}
\Delta v_{\text {model }} \sim \frac{g}{f \theta} \cdot\left(\frac{\partial \theta}{\partial x}\right)_{z_{i}} \Delta z_{i} \approx \frac{9.8}{-5 \times 10^{-5} \times 300} \\
\cdot 1.2 \times 10^{-5} \cdot 400 \approx-3\left(\mathrm{~m} \mathrm{~s}^{-1}\right),
\end{gathered}
$$

which is similar to the forecast value $\sim 2-5 \mathrm{~m} \mathrm{~s}^{-1}$ (Fig. 7). The mean jump in the RHB $\Delta v_{\mathrm{RHB}}$ across the inversion can also be estimated in a similar fashion. That is, $\Delta v_{\mathrm{RHB}} \sim$ $-4 \mathrm{~m} \mathrm{~s}^{-1}$ for a $12 \mathrm{~K}$ increase in $\theta$ across the inversion and a $700 \mathrm{~m}$ increase in $z_{i}$ over 13 degrees of longitude. This value is at the lower end of the observed range from -4 to $-7 \mathrm{~m} \mathrm{~s}^{-1}$ shown in Fig. 7, and is consistent with the estimate by Bretherton et al. (2010) using multi-platform observations. The jumps from the model, however, are weaker than those from the observations at both the "offshore" and "midway' locations, while it is stronger at the "nearshore". This is consistent with an underprediction of $z_{i}$ both near the coast and at the most western locations, resulting in a gentler slope of $z_{i}$ offshore and a steeper one nearshore.

CIRPAS Twin-Otter research flights provide datasets of coastal MBL structure at the fixed location $\left(20^{\circ} \mathrm{S}, 72^{\circ} \mathrm{W}\right)$. Figure 8 compares mean $z_{i}$-normalized boundary layer profiles collected from 18 research flights with the model forecasts at the corresponding times. We first note that the mean predicted MBL height is $751 \mathrm{~m}$, which is about $400 \mathrm{~m}$ lower than that derived from the Twin Otter as shown in Fig. 8a, and consistent with the underprediction of $z_{i}$ found in the nearshore RHB soundings shown in Fig. 7. The mean predicted temperature and moisture within the MBL in general, agrees well with the Twin Otter observations. Both the model results and Twin Otter observations show apparent wind speed and directional shear across the inversion, although the observed changes are significantly stronger than the forecast. The wind direction changes from southerly within the MBL to northerly just above the inversion in both the observations and model simulations. This wind directional shear is also implied by the narrow band (about $500 \mathrm{~km}$ wide) of northerly flow above the MBL as shown in Fig. $2 \mathrm{f}$ near $20^{\circ} \mathrm{S}, 72^{\circ} \mathrm{W}$. Consequently, this wind shear is associated with the meso- or large-scale dynamics, a key difference from the usual wind shear across the inversion, driven by turbulence mixing. This wind shear may introduce significant 

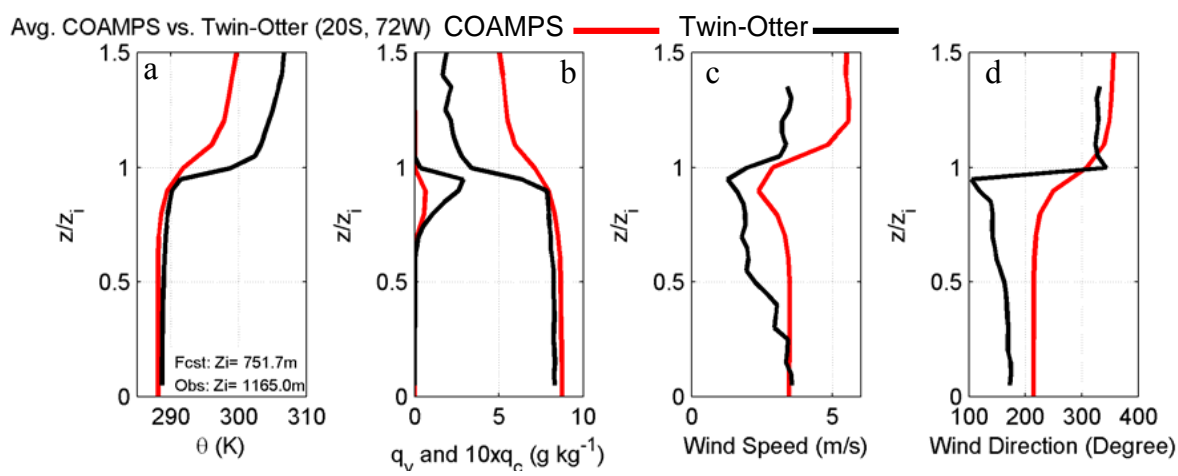

Fig. 8. Comparison between COAMPS and Twin Otter averaged soundings scaled by the boundary layer heights. (a) $\theta$; (b) $q_{v}$ and $10 \times q_{\mathrm{c}}$; (c) wind speed; and (d) wind direction.

turbulence mixing within the entrainment zone, and thus has important implications on the MBL turbulence structure and cloud-top entrainment rate (Wang et al., 2008). It should be noted that, near the surface, the wind direction is $\sim 175^{\circ}$ for the Twin-Otter and $\sim 210^{\circ}$ for the model. Many factors may contribute to the difference, including the timing and strength of the sea breeze, movement of the subtropical high pressure, impacts of steep Andes Mountains, and diurnal variability of the stratocumulus. An examination of the results on the 5-km grid mesh indicates that the 41-day ensemble mean wind direction (not shown here) is $203^{\circ}$, a slight improvement compared with that on the $15-\mathrm{km}$ grid, but not enough to correct the overprediction of the onshore component.

Because of the models' underprediction of $z_{i}$ compared to observations, the simulated $\theta$ just above the MBL is lower than that of the Twin-Otter observations. The air is also moister than the observed by $3 \mathrm{~g} \mathrm{~kg}^{-1}$, further confirming the early result that the air just above the inversion is too moist near the coast in the model compared with the RHB soundings (Fig. 8b). The maximum predicted cloud water $\left(q_{\mathrm{c}}\right)$ is only $0.1 \mathrm{~g} \mathrm{~kg}^{-1}$ compared with the observed value, $0.3 \mathrm{~g} \mathrm{~kg}^{-1}$. The low values of $q_{\mathrm{c}}$ are mainly due to the thinner cloud layer caused by the lower $z_{i}$. This explains the low values of LWP in the forecasts near the coastal area shown in Fig. $3 a$ and Fig. 4.

Longitude-height cross-sections of the simulated 41-day time-averaged $\mathrm{MBL}$ structure along $20^{\circ} \mathrm{S}$ are shown in Fig. 9. Also plotted is the MBL height derived from all the NCAR C- $13020^{\circ} \mathrm{S}$ relative humidity and radar measurements (C. S. Bretherton, personal communication, 2010). In general, the predicted $z_{i}$ increases offshore with increased cloud layer depth. It agrees with the observed $z_{i}$ reasonably well offshore between $85^{\circ} \mathrm{W}$ to $75^{\circ} \mathrm{W}$, particularly between $78^{\circ} \mathrm{W}$ and $75^{\circ} \mathrm{W}$. The predicted $z_{i}$, however, falls sharply near the coast to the east of $75^{\circ} \mathrm{W}$, consistent with the comparison with the RHB and Twin-Otter soundings (Figs. 7 and 8.) The average cloud base in the model is higher than the lifting condensation level (LCL). This difference (cloud base level minus LCL) sharply increases from the coast to about
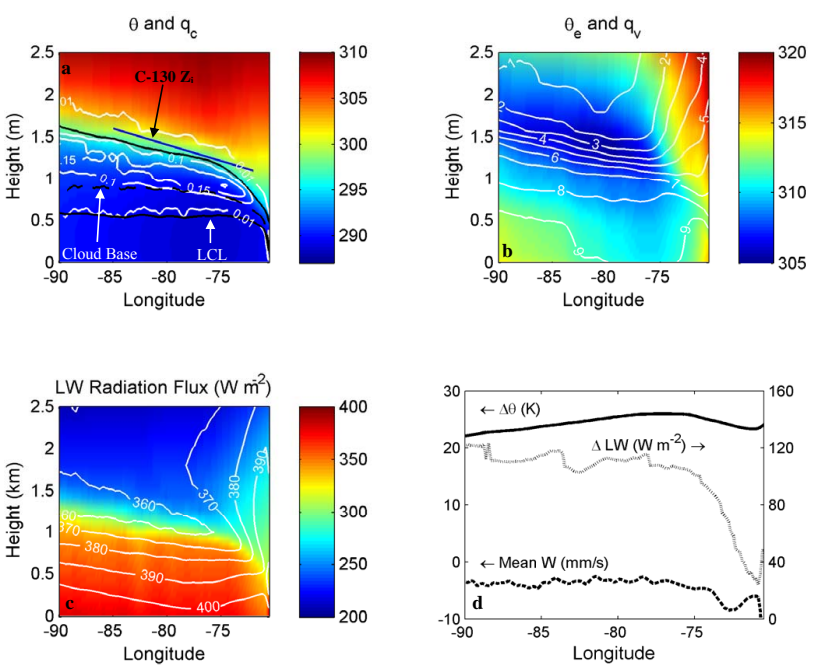

Fig. 9. COAMPS MBL variations along $20^{\circ} \mathrm{S}$. (a) Longitudeheight cross-section of $q_{\mathrm{c}}$ (white contours in $\mathrm{g} \mathrm{kg}^{-1}$ ) and $\theta$ (color shading in $\mathrm{K}$ ). The mean predicted MBL height is denoted by the upper branch of black curve, the mean LCL by the lower branch of the black curve, mean cloud base by the black dashed curve. The blue line is the MBL height fitted by C-130 data. (b) cross sections of $q_{v}$ (white contours in $\mathrm{g} \mathrm{kg}^{-1}$ ) and $\theta_{e}$ (color shading in $\mathrm{K}$ ); (c) cross sections of downward LW flux (color shadeing in $\mathrm{W} \mathrm{m}^{-2}$ ) and upward LW flux (white contours); and (d) predicted longitudinal variations of the lower troposphere stability $\left(\Delta \theta=\theta_{3 \mathrm{~km}}-\theta_{\mathrm{SST}}\right.$, solid line in $\mathrm{K}$ ), the time averaged vertical motion at the inversion height (dashed line in $\mathrm{mm} \mathrm{s}^{-1}$ ) and the total LW divergence across the cloud layer $\left(\Delta \mathrm{LW}\right.$, dotted in $\mathrm{Wm}^{-2}$ ). $\Delta \mathrm{LW}$ is defined as the difference between the total LW radiative flux just above clouds and that just below the cloud base.

$76^{\circ} \mathrm{W}$ and then increases more gently toward the open ocean, suggesting that the MBL becomes decoupled to the west of $76^{\circ} \mathrm{W}$. That is, the MBL thermodynamic profiles depart from being well-mixed and become more stratified due to stronger cloud-top entrainment (Bretherton and Wyant, 1997). 
The predicted moisture above the inversion stays constant at about $2 \mathrm{~g} \mathrm{~kg}^{-1}$ offshore (Fig. 9b); it increases significantly to the east of $76^{\circ} \mathrm{W}$. Because of this increase in moisture, the downward LW flux above clouds increases from $230 \mathrm{~W} \mathrm{~m}^{-2}$ at $80^{\circ} \mathrm{W}$ to $300 \mathrm{~W} \mathrm{~m}^{-2}$ at $72^{\circ} \mathrm{W}$, as shown in Fig. $9 \mathrm{c}$. The strong gradient in the downward LW flux at the cloud top indicates large LW divergence, producing the intense LW radiative cooling that is a main driver of the turbulence in the MBL. The minimum upward LW flux near the cloud top reflects the effect of minimum temperatures at these levels. Owing primarily to the increase in the moisture above the cloud toward the coast, the LW divergence decreases, resulting in the reduced total LW forcing in the cloud layer nearshore, as demonstrated in Fig. 9d. This trend agrees with the RHB and NCAR C-130 observations; it has dynamic implications on the MBL turbulence and cloud structure. Bretherton et al. (2010) presents observational evidence that the westward decrease in moisture above clouds contributes to the westward increase in the LW radiative divergence in the MBL, and consequently, to the corresponding increase in the turbulence intensity and the MBL height.

The overall increase in the MBL height and the more decoupled structure offshore are both consistent with an offshore decrease of lower troposphere stability, as defined here by $\Delta \theta=\theta_{3 \mathrm{~km}}-\theta_{\text {sst }}$ (Fig. 9d) (Bretherton and Wyant, 1997; Klein, 1997). The 41-day averaged predicted vertical velocity at the inversion height level, presented in Fig. 9d, reaches a minimum $\left(\sim-0.81 \mathrm{~cm} \mathrm{~s}^{-1}\right)$ at $72.3^{\circ} \mathrm{W}$ compared to the values of -0.3 to $-0.4 \mathrm{~cm} \mathrm{~s}^{-1}$ to the west of $75^{\circ} \mathrm{W}$. This suggests that the unusually strong subsidence in the model forecasts is likely a main contributor to the thinning of the MBL along the coast. Further analysis will be given in Sect. 7 on the issue of the predicted low MBL heights nearshore.

In Sect. 3, the cloud diurnal amplitude field was shown to be spotty compared to satellite observations (Fig. 4a). Similar spotty cloud fields were also seen in the real-time forecast presentations during VOCALS-REx daily weather briefings. There is strong evidence that these sporadic cloud fields are likely linked to the so-called grid-scale convection due to the lack of a subgrid-scale shallow cumulus convection parameterization. These sporadic cloud features are more clearly seen in Fig. 10a, which displays a longitude-time cross-section of the predicted LWP along $20^{\circ} \mathrm{S}$. Apparent are the appearance of short-lived and thick clouds (LWP 500$700 \mathrm{~g} \mathrm{~m}^{-2}$ ) in the background of a well-defined diurnal variation of relatively thin clouds (LWP $\sim 100-150 \mathrm{~g} \mathrm{~m}^{-2}$ ). Most of the spotty and thick clouds form offshore, where $\theta_{e}$ and $q_{v}$ in the lower MBL increase westward and decrease with height due to the increase in SST (Figs. 2a and 9b). The decoupled MBL offshore also tends to build up moisture in the subcloud layer by inhibiting upward moisture transport from the subcloud layers. These are favorable conditions for the formation of shallow cumulus clouds. Since there is no shallow cumulus convection parameterization in the model, the instability must then be released by grid-scale convec-
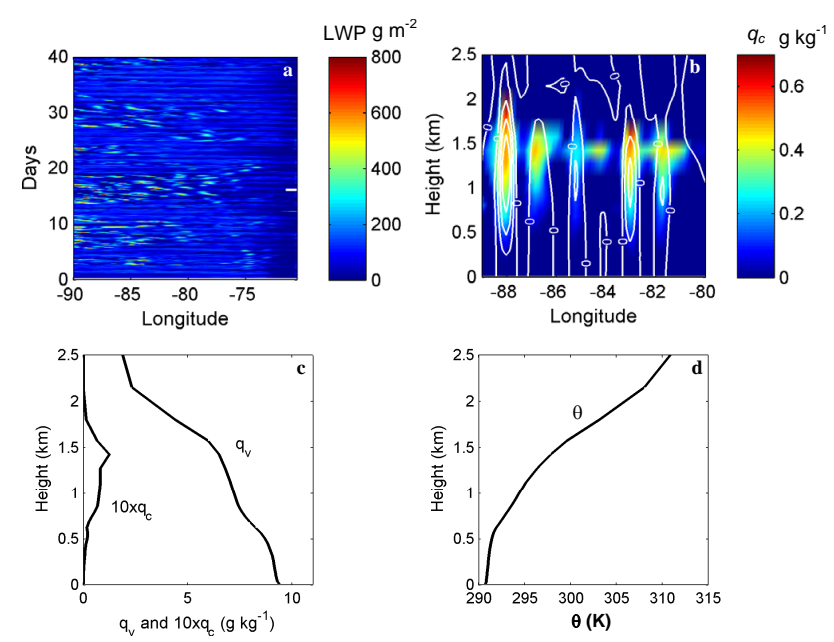

Fig. 10. Examples of grid-scale convection in the COAMPS simulation. (a) Longitude-time cross-section of the COAMPS LWP along $20^{\circ} \mathrm{S}$, (b) longitude-height cross-section of the instantaneous $q_{\mathrm{c}}$ (color shading) and $w$ (contours starting at $0 \mathrm{~cm} \mathrm{~s}^{-1}$ with an interval of $5 \mathrm{~cm} \mathrm{~s}^{-1}$ ) along 20 $\mathrm{S}$ at 03:00 UTC 5 November 2008 [denoted by the white bar on the right axis in a], (c) mean profiles of $q_{v}$ and $q_{\mathrm{c}}$ averaged between $89^{\circ} \mathrm{W}$ and $80^{\circ} \mathrm{W}$, and (d) mean profile of $\theta$.

tion in the MBL, which leads to the formation of the spotty and relatively thick clouds. A snapshot of these clouds is provided in Fig. 10b, where grid-scale updrafts of $15 \mathrm{~cm} \mathrm{~s}^{-1}$ produce clouds with $1.5 \mathrm{~km}$ in depth and $70 \mathrm{~km}$ in width. The overall MBL structure averaged between $90^{\circ} \mathrm{W}$ and $80^{\circ} \mathrm{W}$ at this time (Fig. 10c and d) shows a common shallow cumulus thermodynamic structure consisting of a surface-based mixed layer, a thin stable layer at the cloud base, a cloud layer and an inversion layer at the cloud top (e.g. Albrecht et al., 1995; and Stevens, 2007).

The grid-scale convection may increase the diurnal amplitude if it occurs in the early morning when the cloud LWP is likely at the peak; it may also interrupt the natural diurnal cycle by producing additional thick clouds in the afternoon. Both scenarios occur as the episodic convection is produced during both day and night as demonstrated in Fig. 10a. For areas where the convection is not frequently present (e.g., to the east of $75^{\circ} \mathrm{W}$ and between $19^{\circ} \mathrm{S}$ and $24^{\circ} \mathrm{S}$ from Figs. 4a$\mathrm{d}$ and 10a), the forecast diurnal amplitude and correlation coefficient appear to be in better agreement with the satellite data. A shallow cumulus parameterization like that developed by Park and Bretherton (2009) or by Golaz et al. (2002) may be implemented in COAMPS to address this issue with anomalous grid-scale shallow convection.

In summary, the COAMPS model forecast captures the basic large-scale variability of the MBL along $20^{\circ} \mathrm{S}$, including the general increase in the MBL heights toward the open ocean, the more decoupled MBL structure offshore and the directional wind shear near the coast. The upward slope of 
the MBL height toward the west is consistent with the decrease in meridional wind speed across the inversion based on the thermal wind relationship. The analysis of the instantaneous and averaged MBL structure suggest that the sporadic features in the cloud field (e.g. Figs. 4a and 10a) is likely a result of the lack of shallow cumulus convection parameterization in the model. The comparisons with RHB and aircraft soundings consistently show a relatively large underprediction of the MBL heights in the nearshore area, which may adversely impact the cloud prediction. We show in Sect. 7 that this underprediction in MBL heights near the coast by the model, in part, result from the coarse horizontal and vertical resolution, which notably affects the vertical motion and horizontal advection associated with the steep slope of the Andes.

\section{Surface statistics}

This section focuses on the evaluation of predicted surface variables with the observations collected during the RHB cruises and at the WHOI buoy moored at $20^{\circ} \mathrm{S}, 85^{\circ} \mathrm{W}$. Figure 11 displays longitudinal variations of surface variables from the RHB observations and model forecast data along $20^{\circ} \mathrm{S}$. To better display the general trend of the variables, we first group the data into 1-degree longitude bins and then average them over each group. The temperature, wind speed and water vapor mixing ratio are measured at $15-18 \mathrm{~m}$ height on the RHB, and therefore they are converted to the $10-\mathrm{m}$ level temperature according to the Monin-Obuhkov Similarity theory. The model NCODA SST closely follows the RHB SST variation, reaching local minimum values near $78^{\circ} \mathrm{W}$ and $75^{\circ} \mathrm{W}$ and increasing toward the coast as well as the open ocean. It is also, in part, responsible for the strong lower tropospheric stability between $78^{\circ} \mathrm{W}$ and $76^{\circ} \mathrm{W}$ (Fig. 9d). Reflecting the SST variation, both the predicted and RHB $10-\mathrm{m}$ air temperature $\left(T_{10 \mathrm{~m}}\right)$ have low values near $78^{\circ} \mathrm{W}$ and $75^{\circ} \mathrm{W}$. The modeled SST and $T_{10 \mathrm{~m}}$ have biases of 0.22 and $-0.67^{\circ} \mathrm{C}$, respectively, and correlation coefficients of 0.83 and 0.71 , respectively, showing good agreement with the observations. The predicted $10-\mathrm{m}$ specific humidity $\left(q_{v 10 \mathrm{~m}}\right)$ follows the RHB near the coast and shows a general increasing trend with the increasing SST offshore (Fig. 11c). However, the overall correlation is low (0.25) and the bias is $0.44 \mathrm{~g} \mathrm{~kg}^{-1}$. The predicted wind speed increases from $4 \mathrm{~m} \mathrm{~s}^{-1}$ nearshore to $7 \mathrm{~m} \mathrm{~s}^{-1}$ at $84^{\circ} \mathrm{W}$, consistent with the RHB observations. Its local variation is also comparable with the RHB observations. The wind speed has a low bias $\left(-0.31 \mathrm{~m} \mathrm{~s}^{-1}\right)$ and a relatively high correlation coefficient of 0.76 .

The comparison statistics between the COAMPS forecasts and the WHOI buoy are presented in Table 1. The temperature and wind statistics are in general very similar to previous analyses of COAMPS forecasts over the area along the US west coast (e.g., Doyle et al., 2009). The shortwave (SW)
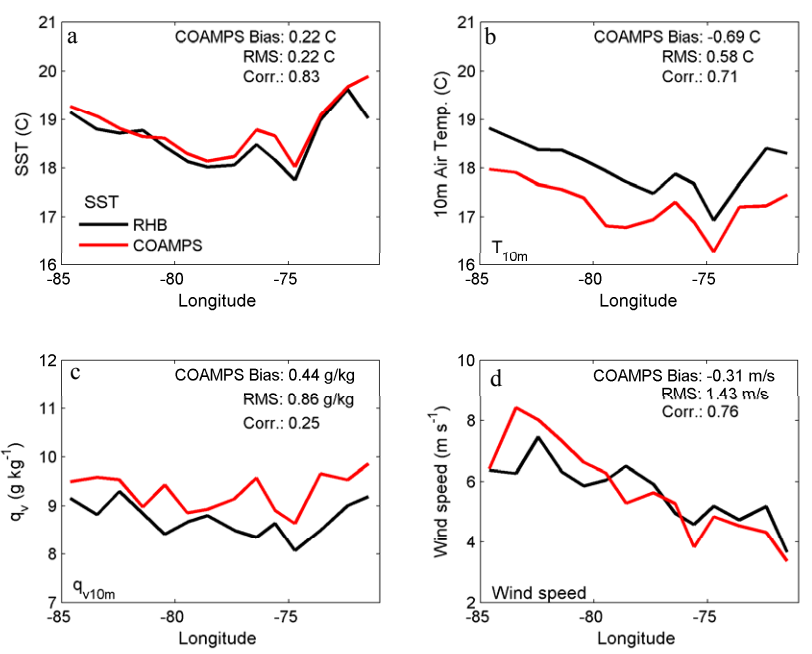

Fig. 11. Comparisons of longitudinal variations at $20^{\circ} \mathrm{S}$ of (a) $\mathrm{SST}$, (b) $T_{10 \mathrm{~m}}$, (c) $q_{v 10 \mathrm{~m}}$, and (d) $10-\mathrm{m}$ wind speed between the COAMPS forecasts and the RHB observations. All the plots are produced by averaging each variable into 1-degree longitude bins using the corresponding RHB and COAMPS data. The overall statistics (bias, RMS difference, and correlation coefficient) for the COAMPS-RHB comparisons are also displayed in each panel.

downward radiative flux from the forecasts has large RMS error compared to the buoy observations, suggesting that the cloud-radiation interaction is not well simulated. The longwave downwelling flux at the surface correlates poorly with that observed at the buoy ( 0.2 in Table 1$)$.

To better understand the model radiative flux errors, we examine scatter plots of the LW fluxes between the forecasts and the observations collected at both the RHB and WHOI buoy (Fig. 12). Each scatter plot displays a "square" pattern with very similar corresponding values at the four corners. Presence of clouds would significantly increase the downward LW flux. Particularly, when the cloud layer is thick enough to radiate as a blackbody, the thermal radiation by the cloud is saturated and depends only on the cloud layer temperature. To examine the effects of clouds, we separate the "thick clouds" data points from "clouds free" ones using LWP from COAMPS and those measured by the RHB thermal infrared radiometer. The "thick cloud" condition (blue points) is defined here as a LWP greater than $30 \mathrm{~g} \mathrm{~m}^{-2}$ in both the observations and forecasts; conversely, the "clouds free" condition (green points) is defined as LWP less than $1 \mathrm{~g} \mathrm{~m}^{-2}$ for both data sets. These definitions are chosen because they successfully stratify the data, and our results are not particularly sensitive to the exact cutoff LWP values. As shown in Fig. 12a, the blue cluster at the upper-right corner of the "square" corresponds to the condition where both the observations and COAMPS forecasts are designated as "thick clouds", while the green cluster at the lower-left corner indicates the "clouds free" condition. The average of all 
Table 1. Statistical comparisons between the COAMPS forecasts and the WHOI buoy observations. Correlation coefficients in the last row do not have any units.

\begin{tabular}{lrrrrrr}
\hline & $T(\mathrm{~K})$ & $u\left(\mathrm{~m} \mathrm{~s}^{-1}\right)$ & $v\left(\mathrm{~m} \mathrm{~s}^{-1}\right)$ & $\begin{array}{r}\text { Speed } \\
\left(\mathrm{m} \mathrm{s}^{-1}\right)\end{array}$ & $\begin{array}{r}\text { LW downward } \\
\left(\mathrm{W} \mathrm{m}^{-2}\right)\end{array}$ & $\begin{array}{r}\text { SW downward } \\
\left(\mathrm{W} \mathrm{m}^{-2}\right)\end{array}$ \\
\hline Bias & -0.43 & -0.51 & 1.00 & 0.35 & 2.68 & -7.74 \\
RMS & 0.47 & 1.54 & 1.66 & 1.35 & 26.02 & 188.68 \\
Corr. & 0.62 & 0.52 & 0.47 & 0.62 & 0.20 & 0.84 \\
\hline
\end{tabular}
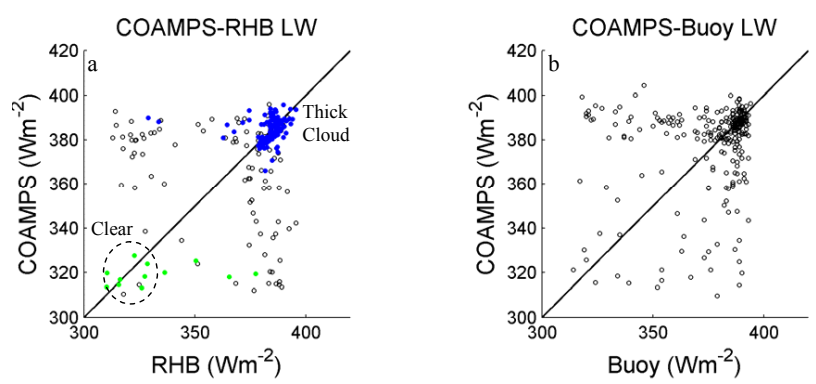

Fig. 12. Scatter plots of surface downward LW between observations and COAMPS forecasts. (a) COAMPS vs. RHB; and (b) COAMPS vs. Buoy. The "clear" condition (green points) is defined here as LWP less than $1 \mathrm{~g} \mathrm{~m}^{-2}$ from both the COAMPS and the RHB; The "thick cloud" (blue points) is defined as LWP greater than $30 \mathrm{~g} \mathrm{~m}^{-2}$ from both the COAMPS and the RHB.

RHB clear-sky downward LW fluxes of $315 \mathrm{~W} \mathrm{~m}^{-2}$ is close to the values within the "clouds free" circle. Since the majority of the "blue" and "green" data points are located along the one-to-one correlation line, the LW radiative fluxes for both the "clouds free" and "thick clouds" conditions are therefore well simulated by the model. These clusters of points account for $50 \%$ of all data points (117 out of 235 total). Large radiative flux errors occur when cloud conditions are very different between the forecast and observation datasets. For example, the points at the upper-left corner with values centered at $(320,380)$ represent the "clouds free" condition in the observations and the "thick clouds" in the COAMPS forecasts. The points along the right-hand-side vertical line of the square (i.e., $\mathrm{RHB} \cong 380 \mathrm{~W} \mathrm{~m}^{-2}$ ) indicate that the "thick clouds" conditions from the RHB are associated with thin cloud or partial cloudiness conditions in the model. This LW comparison raises two issues related to the cloud-radiation interaction modeling. One is the realistic prediction of $q_{\mathrm{c}}$ and partial cloudiness; the other is the physical representation of these cloud variables in the radiation calculation. Both issues need to be further addressed to improve the radiation modeling in the future.

\section{Diurnal variation of marine boundary layer structure}

Section 2 presents the regional cloud variation of the MBL diurnal cycle as derived from both the model forecasts and satellite data. This section focuses on the comparison between the forecast and observed diurnal cycle of MBL structure. RHB rawindsondes were launched six times daily at approximately 00:00, 04:00, 08:00, 12:00, 16:00, and 20:00 (UTC). These measurements provide adequate sampling of the diurnal variation of the MBL structure. The model forecast soundings are averaged at the observation times to produce the mean diurnal cycles for both the forecasts and the RHB observations. To reduce the effects of the longitudinal variations of MBL heights, we normalize the sounding profiles using the MBL heights before averaging.

As shown in Fig. 13, both the MBL heights $\left(z_{i}\right)$ calculated from the RHB and the model undergo a well-defined diurnal cycle with the maximum in the morning and the minimum in the afternoon. This diurnal cycle is consistent with our general understanding that the daytime solar cloud absorption tends to suppress turbulent intensity and reduce cloud amount, leading to weaker cloud-top entrainment and a shallower boundary layer. Both the forecast and the observed $z_{i}$ reach a maximum around 06:00 LST. The RHB $z_{i}$ obtains its minimum at 15:00 LST, $4 \mathrm{~h}$ earlier than in the forecasts. The RHB $z_{i}$ is, on average, $140 \mathrm{~m}$ higher than in the forecasts. Its diurnal amplitude is $130 \mathrm{~m}$ compared to only $60 \mathrm{~m}$ for that of the COAMPS $z_{i}$, which is consistent with our earlier result that the diurnal amplitude of the satellite LWP is in general larger than the COAMPS as shown in Fig. 4.

Figure 14 compares the MBL structure from the RHB and the forecasts. To better present the results, we only show the profiles at 06:54, 14:50 and 22:30 (LST). The general trend of the MBL warming during the daytime is the same in both the forecasts and the RHB observations, as shown by the $\theta$ profiles in Fig. 14a and b. The MBL temperature increases with the daytime cloud-layer solar warming, creating a more stratified structure at 14:50 LST. In the evening, the cloud layer cools down as the cloud solar warming diminishes and the cloud-top longwave cooling dominates again. There are clear differences in the $\theta$ profiles between the observed and predicted at 14:50 LST. The RHB $\theta$ demonstrates a three-layered structure with a thin stable layer at 


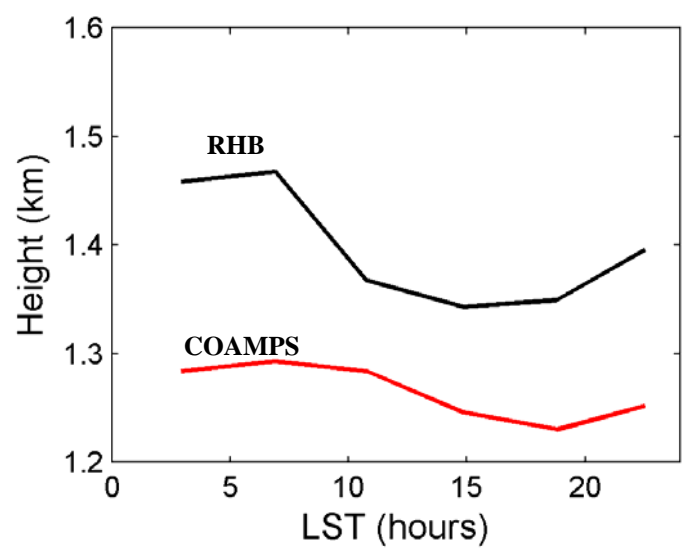

Fig. 13. Diurnal variations of mean MBL heights computed from the RHB soundings (black) and the COAMPS forecasts (red).

$0.6 z / z_{i}$, separating the upper stratocumulus clouds from the surface-based subcloud layer. The COAMPS $\theta$ profile has a smoothly transitioned two-layered (cloud and subcloud layer) structure. These differences suggest that the predicted daytime MBL has a less decoupled structure than the observations, which is consistent with the differences in the cloud layer warming shown between the forecast soundings ( $0.6 \mathrm{~K}$ between 07:00 and 14:50 LST) and the RHB (0.8 K) shown in Fig. 14.

The COAMPS $q_{v}$ is larger in general and has less diurnal variability than the RHB, as shown in Fig. 14c and d. A twolayer structure for all the COAMPS $q_{v}$ soundings is clearly seen with the subcloud layer being nearly well-mixed. In contrast, the RHB $q_{v}$ profile has a multi-layered structure at 14:45 LST, being consistent with the RHB $\theta$ profile at the same time. The maximum diurnal change in $q_{v}$ from the COAMPS is only $0.25 \mathrm{~g} \mathrm{~kg}^{-1}$ compared to $0.5 \mathrm{~g} \mathrm{~kg}^{-1}$ from the RHB soundings.

Associated with these diurnal changes in the predicted $\theta$ and $q_{v}$, the $q_{\mathrm{c}}$ and TKE also undergo similar corresponding changes, as shown in Fig. $14 \mathrm{e}$ and $\mathrm{f}$. The $q_{\mathrm{c}}$ maximum is $0.35 \mathrm{~g} \mathrm{~kg}^{-1}$ at $06: 54 \mathrm{LST}$, and decreases to $0.15 \mathrm{~g} \mathrm{~kg}^{-1}$ at 14:50 LST. The lower cloud layer with small $q_{\mathrm{c}}$ represents shallow cumulus clouds underneath the main stratocumulus layer between 0.6 and $1 z / z_{i}$. A significant reduction in TKE from early morning to afternoon is apparent, particularly in the cloud layer (Fig. 14d). The minimum values of the TKE profiles near the mid-MBL indicate that the cloud layer tends to decouple from the subcloud layer.

\section{Sensitivity of MBL structure to grid resolution}

The evaluation of the COAMPS forecasts shows that the MBL heights close to the coast are significantly lower than in the observations (Figs. 7-9). This deficiency appears to be quite common among many global and regional models as
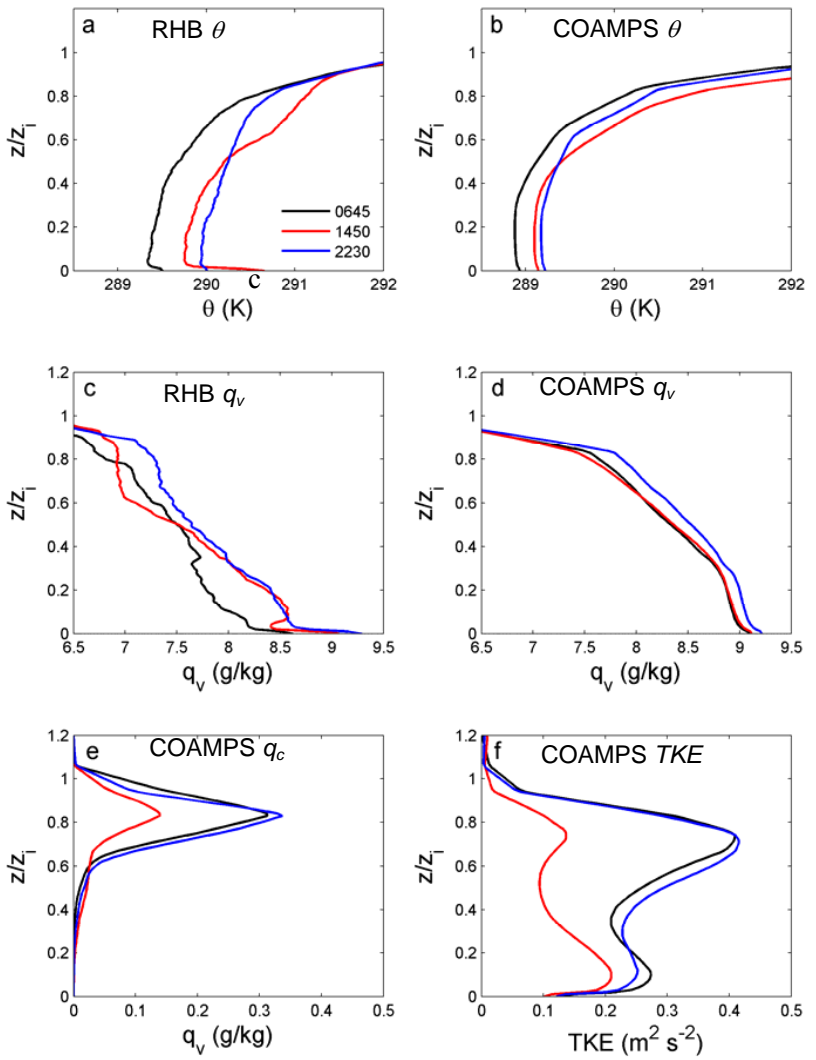

Fig. 14. Diurnal variation of normalized profiles from the RHB observations and the COAMPS forecasts. (a) RHB $\theta$; (b) COAMPS $\theta$; (c) RHB $q_{v}$; (d) COAMPS $q_{v}$; (e) COAMPS $q_{\mathrm{c}}$; and (f) COAMPS $T K E$. The numbers in (a) denote local time of the soundings defined by the different colors.

discussed by Wyant et al. (2010). This consistent bias among the models promotes us to further analyze the prediction results at different horizontal and vertical resolutions.

We first compare the averaged MBL structure on three nested grid meshes $(45 \mathrm{~km}, 15 \mathrm{~km}$, and $5 \mathrm{~km})$ at two locations: nearshore at $72^{\circ} \mathrm{W}$ and $20^{\circ} \mathrm{S}$, and offshore at $76^{\circ} \mathrm{W}$ and $20^{\circ} \mathrm{S}$. By increasing the horizontal resolution from $45 \mathrm{~km}$ to $5 \mathrm{~km}$, the MBL height at the nearshore location increases by $250 \mathrm{~m}$ and the temperature by $1 \mathrm{~K}$ at $72^{\circ} \mathrm{W}$ (Fig. 15). Correspondingly, $q_{\mathrm{c}}$ increases by $50 \%$ to $0.15 \mathrm{~g} \mathrm{~kg}^{-1}$ at the finest grid mesh $(5 \mathrm{~km})$. The higherresolution grid clearly tends to improve the predicted MBL structure and clouds at the nearshore location. On the contrary, the higher-resolution grid has little impact on the MBL structure at the offshore location. This difference implies that the improvement for the nearshore MBL is likely caused by changes in mesoscale motions due to the high-resolution grid.

Figure 15 further shows that changes in downward motion and total $\theta$ advection between the coarse and fine resolution grids are likely responsible for these structural changes at 

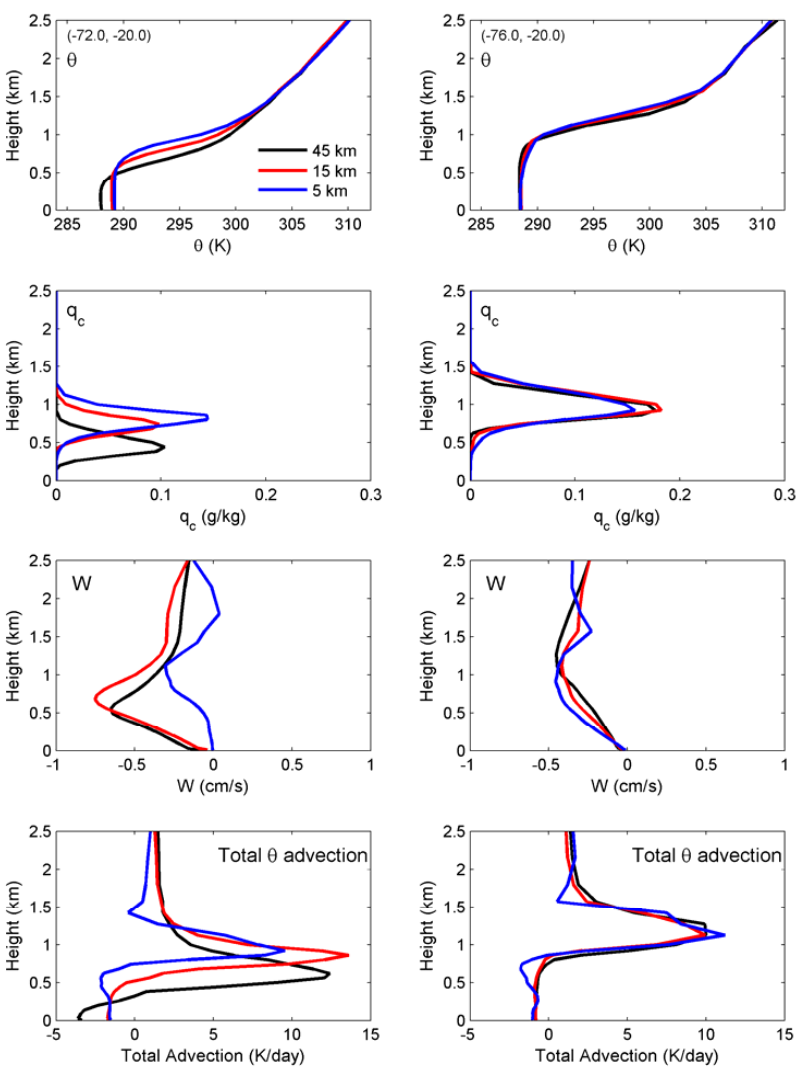

Fig. 15. Comparison of the averaged MBL structure and mesoscale forcing among different resolution grids and locations. Left column of panels are results from the nearshore location at $72^{\circ} \mathrm{W}$ and $20^{\circ} \mathrm{S}$; the right column the offshore location at $16^{\circ} \mathrm{W}$ and $20^{\circ} \mathrm{S}$; the horizontal resolutions ( $45 \mathrm{~km}, 15 \mathrm{~km}$ and $5 \mathrm{~km}$ ) are denoted in the top-right panel, the letters or words in each plot denote the variables.

$72^{\circ} \mathrm{W}$ and $20^{\circ} \mathrm{S}$. The finest-resolution mesh $(5 \mathrm{~km})$ results in the weakest subsidence at the MBL height, leading to the highest MBL height among the three grid meshes. The total 3-dimensional $\theta$ advection in the $45 \mathrm{~km}$ grid mesh gives the largest cooling rate near the surface; that is double that from the other grid meshes. The total advection near the surface mainly represents just the horizontal component, because the vertical advection is very small. Consequently, this large horizontal advective cooling and the strong wind divergence tend to strengthen the cloud-top inversion and limit the MBL growth, resulting in the lowest MBL height in the $45 \mathrm{~km}$ grid mesh. It should be noticed that the subsidence and the total advection heating are very similar among the three grid meshes at $76^{\circ} \mathrm{W}$ and $20^{\circ} \mathrm{S}$, which is consistent with the similar MBL heights predicted at the offshore location.

Effects of vertical resolution on the forecast MBL are also evaluated by conducting another model simulation with an enhanced vertical resolution of 95 levels (50 levels below $2 \mathrm{~km}$ ) compared to the 45 (23 levels below $2 \mathrm{~km}$ ) in the real- time forecast. The 48 -h sensitivity simulation is initialized at 00:12 UTC on 22 October 2008 and its time-averaged results are shown in Fig. 16. Apparent in this figure is that the increase in vertical resolution leads to increases of MBL heights for all three grids near the coast; the mean MBL height increases the most for the $5 \mathrm{~km}$ grid, with differences of $\sim 300 \mathrm{~m}$. The increased vertical resolution has little impact on the MBL structure offshore (not shown here). Associated with the increase in the MBL height, the maximum $q_{\mathrm{c}}$ increases for the $15 \mathrm{~km}$ and $5 \mathrm{~km}$ grid due to the cloud thickening. Figure 16 also makes an important point that the high-vertical resolution produces weaker subsidence in the MBL than the control forecast for all three grids. For the finest $(5 \mathrm{~km})$ grid mesh, the high-resolution simulation gives the weakest subsidence and produces the highest MBL height. There is therefore a clear correlation between the increased MBL heights and the weakened subsidence within and just above the MBL produced by the increased vertical and horizontal resolution meshes.

The above results suggest that the increases in both the horizontal and vertical resolutions lead to the improvements in the simulated MBL heights and clouds near the coast, and these improvements may come from better defined coastal circulations. Increasing the horizontal resolution better resolves the topography and coastal flows. The increase in the vertical resolution likely reduces numerical errors associated with gradient calculations near a steep terrain. This is consistent with some previous studies demonstrating that numerical treatment of mountain slopes is critical for a realistic simulation of local mesoscale circulations (e.g. Zängl, 2002). However, the details about the dependence of coastal mesoscale circulations on the model resolutions and numerical techniques are beyond the scope of this study.

\section{Summary}

COAMPS was employed to provide twice-daily $48 \mathrm{~h}$ forecasts during VOCALS-REx in October and November 2008. The model was configured with three nested grid meshes $(45 \mathrm{~km}, 15 \mathrm{~km}$ and $5 \mathrm{~km})$ and 45 vertical levels to cover the large experiment area with adequate resolution. The MBL structure from the real-time forecasts are evaluated and validated, with an emphasis on results from the $15 \mathrm{~km}$ grid mesh, against observations taken on a number of platforms, including aircraft, ship, buoy and satellites.

The regional distributions of the 41-day averages of predicted LWP and wind speed are generally in agreement with those observed by satellite, although the modeled LWP is slightly smaller and wind speed larger in the VOCALS-REx region. The overall location, direction and strength of the southerly coastal jet along the Chilean coast are correctly predicted. The harmonic regression analysis shows that the phase of diurnal variation of the MBL clouds and the surface wind speed are in general consistent with the satellite data 

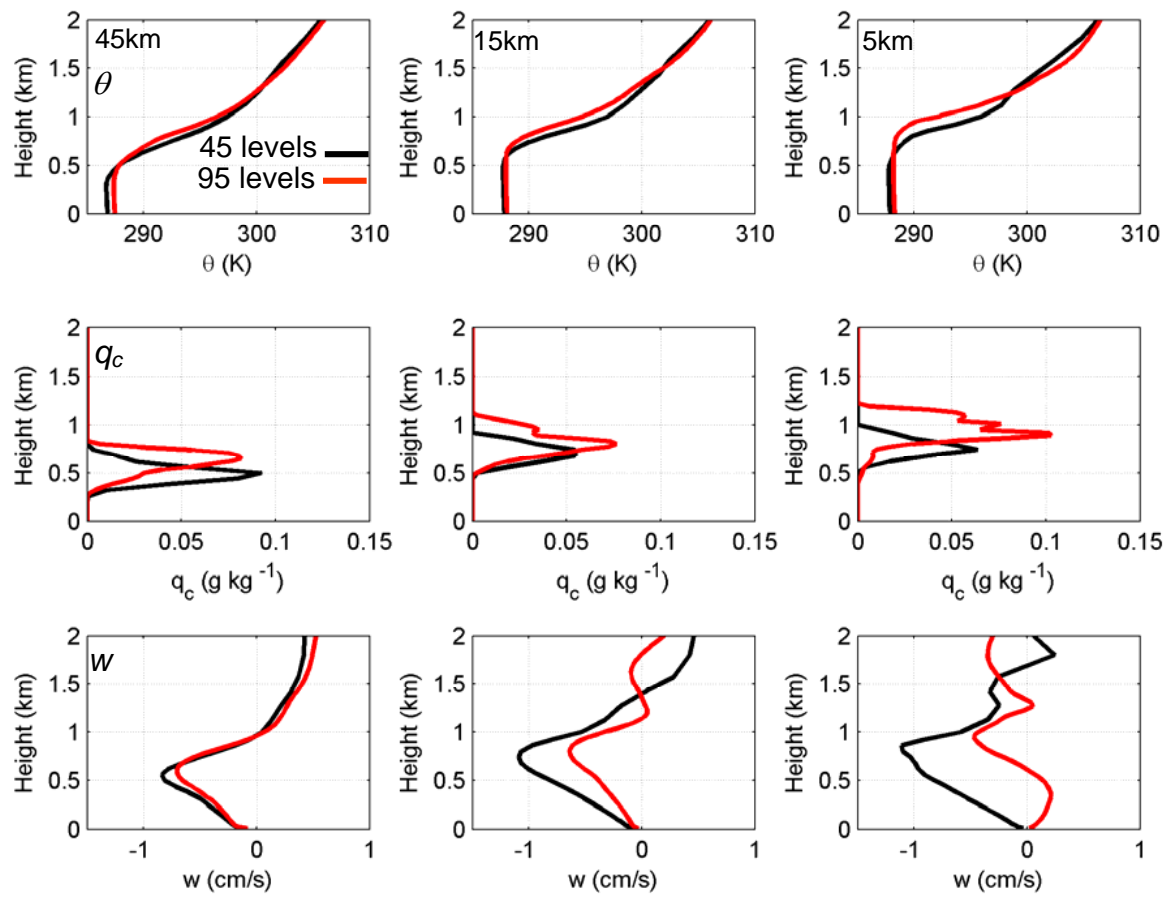

Fig. 16. Comparison of the $48 \mathrm{~h}$-averaged MBL profiles between the control ( 45 levels) and the high-vertical resolution ( 95 levels) simulation at $72^{\circ} \mathrm{W}$ and $20^{\circ} \mathrm{S}$. Upper panels: $\theta$; and middle panels: $q_{\mathrm{c}}$; and the lower: $w$. The control forecast is denoted by black curves; and the high resolution by the red. The horizontal resolution is $45 \mathrm{~km}$ for the left panels, $15 \mathrm{~km}$ for the central, and $5 \mathrm{~km}$ for the right.

except for the coastal area off Peru. The diurnal amplitude of the predicted LWP exhibits a spotty spatial distribution compared to the smooth distribution of the satellite data. We have shown that this spotty distribution is caused by grid-shallow convection likely due to a lack of a shallow cumulus convection parameterization in the model.

The forecast-observation comparisons along $20^{\circ} \mathrm{S}$ demonstrate overall consistency in some basic MBL characteristics, including a general upward slope in the MBL height, a more decoupled boundary layer structure toward the west, and maximum wind speeds near the top of the MBL. Both the forecasts and the observations show a trend of decreasing moisture above the MBL away from the coast, resulting in stronger radiative cooling near the cloud tops offshore. The more decoupled MBL structure with upward slope in the MBL height toward west is primarily driven by the westward decrease in the lower troposphere stability, which enhances the cloud-top entrainment. This is also consistent with the increased LW radiative forcing offshore. The model analyzed SST, predicted 10-m air temperature and surface wind speed yield realistic zonal variations along $20^{\circ} \mathrm{S}$ compared with ship-based RHB observations. The model consistently predicted a shallower MBL $(\sim 700 \mathrm{~m})$ than what was observed $(\sim 1100 \mathrm{~m})$ in the coastal region. This bias leads to an overall low cloud water mixing ratio in the model forecasts compared to the observations. The overall statistical errors of the surface wind speed and temperature are consistent with previous analyses, with the wind speed bias $\left(<0.35 \mathrm{~m} \mathrm{~s}^{-1}\right)$ and RMS $\left(1.3 \mathrm{~m} \mathrm{~s}^{-1}\right)$ and the temperature bias $(-0.7 \mathrm{~K})$ and RMS $(0.5 \mathrm{~K})$.

The simulated LW on both the "thick cloud" and "clouds free" conditions produce good agreements with the observed values, but it suffers when the prediction of clouds is in error, suggested by the "square" patterns on the model-observation LW scatter plots. This clearly shows the importance of the accurate prediction of cloud water mass and fractional coverage in the determination of LW radiative fluxes.

COAMPS also predicted a well-defined diurnal variation in the temporally and spatially averaged MBL structure, which is generally consistent with the RHB observed $z_{i}, \theta$ and $q_{v}$. The predicted mean structure, however, has smaller diurnal changes in these variables compared to the observations; this feature is also reflected in the smaller diurnal amplitude in the regional LWP diurnal harmonic analysis.

To further understand the underprediction of MBL heights near the coast, we examined the impacts of the model resolution. It was found that higher resolutions in both the horizontal and vertical directions indeed have noticeable positive impacts on the nearshore MBL heights, while having little influence offshore. The simulations with the $5-\mathrm{km}$ grid mesh (45 vertical levels) predicted higher and more realistic MBL height $(\sim 900 \mathrm{~m})$ than those with the $15 \mathrm{~km}$ mesh $(\sim 700 \mathrm{~m})$ or the $45 \mathrm{~km}$ mesh $(\sim 600 \mathrm{~m})$. Enhancing the vertical resolution to 95 levels further increased the MBL height 
to $1100 \mathrm{~m}$ for the $5 \mathrm{~km}$ grid. These improvements are likely due to the changes to the mesoscale flows such as the reduced coastal downward motion and weakened cold advection near the surface produced by the high-resolution forecasts. Given the generality of this bias among regional and global models, and the implications of the resolution study in this work, efforts should be directed to improve simulations of mesoscale flows under the influence of steep terrains.

Acknowledgements. This work was supported by the Office of Naval Research (ONR) under Program Element (PE) 0602435N and by the National Science Foundation (ATM-0749011). The first author thanks the NRL COAMPS-On Scene group for their support for the COAMPS forecasts during VOCALS-REx. COAMPS ${ }^{\circledR}$ is a registered trademark of the Naval Research Laboratory.

Edited by: R. Garreaud

\section{References}

Albrecht, B. A.: Aerosols, cloud microphysics, and fractional cloudiness, Science, 245, 1227-1230, 1989.

Albrecht, B. A., Jensen, M. P., and Syrett, W. J.: Marine boundary layer structure and fractional cloudiness. J. Geophys. Res., 100, 14209-14222, 1995.

Bony, S. and Dufresne, J.-L.: Marine boundary layer clouds at the heart of tropical cloud feedback uncertainties in climate models, Geophys. Res. Lett., 32 L20806, doi:10.1029/2005GL023851, 2005.

Bretherton, C. and Wyant, M. C.: Moisture transport, lowertropospheric stability, and decoupling of cloud-topped boundary layers, J. Atmos. Sci., 54, 148-167, 1997.

Bretherton, C. S., Wood, R., George, R. C., Leon, D., Allen, G., and Zheng, X.: Southeast Pacific stratocumulus clouds, precipitation and boundary layer structure sampled along $20 \mathrm{~S}$ during VOCALS-REx, Atmos. Chem. Phys., 10, 10639-10654, doi:10.5194/acp-10-10639-2010, 2010.

Burk, S. D. and Thompson, W. T.: A vertically nested regional numerical weather prediction model with second-order closure physics, Mon. Weather Rev., 117, 2305-2324, 1989.

Cummings, J.: Operational multivariate ocean data assimilation, Q. J. Roy. Meteorol. Soc., 131, 3583-3604, 2005.

de Szoeke, S. P., Wang, Y., Xie, S.-P., and Miyama, T.: Effect of shallow cumulus convection on the eastern Pacific climate in a coupled model, Geophys. Res. Lett., 33, L17713, doi:10.1029/2006GL026715, 2006.

de Szoeke, S. P., Fairall, C. W., Wolfe, D. E., Bariteau, L., and Zuidema, P.: Surface flux observations on the southeastern tropical Pacific Ocean and attribution of SST errors in coupled oceanatmosphere models, J. Climate, 23, 4152-4174, 2010.

Doyle, J. D., Jiang, Q., Chao, Y., and Farrara, J.: High-resolution real-time modeling of the marine atmospheric boundary layer in support of the AOSN-II field campaign, Deep Sea Res. II, 52, 87-99, doi:10.1016/j.dsr2.2008.08.009, 2009.

Felsch, P. and Whitlatch, W.: Stratus surge prediction along the central California coast, Mon. Weather Rev., 8, 204-213, 1993.
Fu, Q. and Liou, K. N.: On the Correlated $k$-Distribution Method for Radiative Transfer in Nonhomogenecous Atmospheres, J. Atmos. Sci., 49, 2139-2156, 1992.

Garreaud, R. D. and Muñoz, R. C.: The diurnal cycle in circulation and cloudiness over the subtropical southeast pacific: A modeling study, Mon. Weather Rev., 17, 1699-1710., 2004.

Garreaud, R. D. and Muñoz, R. C.: The low-level jet off the west coast of subtropical South America: Structure and variability, Mon. Weather Rev., 133, 2246-2261, 2005.

Gille, S. T., Llewellyn Smith, S. G., and Statom, N. M.: Global observations of the land breeze, Geophys. Res. Lett., 32, L05605, doi:10.1029/2004GL022139, 2005.

Golaz, J.-C., Larson, V. E., and Cotton,W. R: A PDF-based model for boundary layer clouds. Part I: Method and model description, J. Atmos. Sci., 59, 3540-3551, 2002.

Hodur, R. M.: The Naval Research Laboratory's coupled ocean/atmosphere mesoscale prediction system (COAMPS), Mon. Weather Rev., 125, 1414-1430, 1997.

Jiang, Q., Wang, S., and O'Neill, L.: Some insights into the characteristics and dynamics of Chilean low-level coastal jet, Mon. Weather Rev., 138, 3185-3206, 2010.

Kain, J. S. and Fritsch, M.: A one-dimensional entraining/detraining plume model and its application in convective parameterization, J. Atmos. Sci., 47, 2784-2802, 1990.

Klein, S. A.: Synoptic variability of low-cloud properties and meteorological parameters in the subtropical trade wind boundary layer, J. Climate, 10, 2018-2039, 1997.

Klein, S. A. and Hartmann, D. L.: The seasonal cycle of low stratiform clouds, J. Climate, 6, 1587-1606, 1993.

Lilly, D. K.: Models of cloud-topped mixed layers under a strong inversion, Q. J. Roy. Meteorol. Soc., 94, 292-308, 1968.

Liu, M., Nachamkin, J. E., and Westphal, D. L.: On the improvement of COAMPS weather forecasts using an advanced radiative transfer model, Weather Forecast. 24, 286-306, 2009.

Louis, J. F., Tiedtke, M., and Geleyn J. F.: A short history of the operational PBL-parameterization of ECMWF, Proceedings of the 1981 ECMWF workshop on planetary boundary layer parameterization, Shinfield Park, Reading, Berkshire, UK, European Centre for Medium Range Weather Forecasts, 59-79, 1982.

Lorenz, E. N.: Available energy and the maintenance of a moist circulation, Tellus, 30, 241-259, 1978.

Ma, C.-C., Mechoso, C. R., Robertson A. W., and Arakawa, A.: Peruvian stratus clouds and the tropical Pacific circulation: A coupled ocean-atmosphere GCM study, J. Climate, 9, 1635-1645, 1996.

McCaa, J. R. and Bretherton, C. S.: A New Parameterization for Shallow Cumulus Convection and Its Application to Marine Subtropical Cloud-Topped Boundary Layers. Part II: Regional Simulations of Marine Boundary Layer Clouds, Mon. Weather Rev., 132, 883-896, 2004.

Mechem, D. B. and Kogan, Y. L.: Simulating the transition from drizzling marine stratocumulus to boundary layer cumulus with a mesoscale model, Mon. Weather Rev., 131, 2342-2360, 2003.

Mellor, G. L. and Yamada, T.: Development of a turbulence closure for geophysical fluid problems, Rev. Geophys. Space Phys., 20, 851-875, 1982.

Mocko, D. M. and Cotton, W. R.: Evaluation of fractional cloudiness parameterizations for use in a mesoscale model, J. Atmos. Sci., 52, 2884-2901, 1995. 
Muñoz R. C.: Diurnal cycle of surface winds over the subtropical southeast Pacific, J. Geophys. Res., 113, D13107, doi:10.1029/2008JD009957, 2008.

Muñoz, R. C. and Garreaud, R. D.: Dynamics of the Low-Level Jet off the West Coast of Subtropical South America, Mon. Weather Rev., 133, 3661-3667, 2005.

Nicholls, S.: The dynamics of stratocumulus: aircraft observations and comparison with a mixed-layer model, Q. J. Roy. Meteor. Soc., 112, 431-460, 1984.

O’Dell, C. W., Wentz, F. J., and Bennartz, R.: Cloud Liquid Water Path from Satellite-Based Passive Microwave Observations: A New Climatology over the Global Oceans, J. Climate, 8, 17211739, 2008.

Palmen, E. and Newton, C. W.: Atmospheric Circulation System, Academic Press, 603 pp., 1969.

Park, S. and Bretherton, C.: The University of Washington shallow convection and moist turbulence schemes and their impact on climate simulations with the community atmosphere model, J. Climate, 22, 3449-3469, 2009.

Rahn, D. A. and Garreaud, R.: Marine boundary layer over the subtropical southeast Pacific during VOCALS-REx - Part 1: Mean structure and diurnal cycle, Atmos. Chem. Phys., 10, 4491-4506, doi:10.5194/acp-10-4491-2010, 2010a.

Rahn, D. A. and Garreaud, R.: Marine boundary layer over the subtropical southeast Pacific during VOCALS-REx - Part 2: Synoptic variability, Atmos. Chem. Phys., 10, 4507-4519, doi:10.5194/acp-10-4507-2010, 2010 b.

Rozendaal, M. A., Leovy, C. B., and Klein, S. A.: An observational study of diurnal 41 variation of marine stratiform clouds, J. Climate, 8, 1795-1809, 1995.

Rutledge, S. A. and Hobbs, P. V.: The mesoscale and microscale structure of organization of clouds and precipitation in midlatitude cyclones. VIII: A model for the "seeder-feeder" process in warm-frontal rainbands, J. Atmos. Sci., 40, 1185-1206, 1983.

Rutllant, J.: Coastal lows and associated southerly winds in northcentral Chile. Preprints, Fourth Int. Conf. on Southern Hemisphere Meteorology, Hobart, Australia, Amer. Meteor. Soc., 268-269, 1993.

Shulman, I., Kindle, J., Martin, P., deRada, S., Doyle, J., Penta, B., Anderson, S., Chavez, F., Paduan, J., and Ramp, S.: Modeling of upwelling/relaxation events with the Navy Coastal Ocean Model, Deep Sea Res. II, 112, C06023, doi:10.1029/2006JC003946, 2007.

Stevens, B.: On the growth of layers of nonprecipitating cumulus convection, J. Atmos. Sci., 64, 2916-2931, 2007.

Stevens, B., Vali, G., Comstock, K., vanZanten, M. C., Austin, P. H., Bretherton, C. S., and Lenschow, D. L.: Pockets of open cells and drizzle in marine stratocumulus, B. Am. Meteor. Soc., 86, 51-57, 2005.
Thompson, W. T., Burk, S. D., and Lewis, J.: Fog and low clouds in a coastally trapped disturbance, J. Geophys. Res., 110, D18213, doi:10.1029/2004JD005522, 2005.

Wang, H. and Feingold, G.: Modeling mesoscale cellular structures and drizzle in marine stratocumulus. Part I: Impact of drizzle on the formation and evolution of open cells, J. Atmos. Sci., 66, 3237-3256, 2009.

Wang, S., Albrecht, B. A., and Minnis P.: A regional simulation of marine boundary-layer clouds. J. Atmos. Sci., 50, 4022-4043, 1993.

Wang, S., Wang, Q., and Doyle, J.: Some improvement of Louis surface flux parameterization. Preprints, 15th Symp. on Boundary Layers and Turbulence, Wageningen, Netherlands, Amer. Meteor. Soc., 547-550, 2002.

Wang, S., Golaz, J.-C., and Wang, Q.: Effect of intense wind shear across the inversion on stratocumulus clouds, Geophys. Res. Lett., 35, L15814, doi:10.1029/2008GL033865, 2008.

Wang, Y., Xie, S.-P., Xu, H., and Wang, B.: Regional model simulations of marine boundary layer clouds over the southeast Pacific off South America. Part I: Control experiment, Mon Weather Rev., 132, 274-296, 2004a.

Wang, Y., Xu, H., and Xie, S.-P.: Regional model simulations of marine boundary layer clouds over the southeast Pacific off South America. Part II: Sensitivity experiments, Mon. Weather Rev., 132, 2650-2668, 2004b.

Wood, R., Kohler, M., Bennartz, R., and O'Dell, C.: The diurnal cycle of surface divergence over the global oceans, Q. J. Roy. Meteor. Soc., 135, 1484-1493, 2009.

Wood, R., Bretherton, C. S., Mechoso, C. R., Weller, R. A., Huebert, B., Straneo, F., Albrecht, B. A., Coe, H., Allen, G., Vaughan, G., Daum, P., Fairall, C., Chand, D., Gallardo Klenner, L., Garreaud, R., Grados Quispe, C., Covert, D. S., Bates, T. S., Krejci, R., Russell, L. M., de Szoeke, S., Brewer, A., Yuter, S. E., Springston, S. R., Chaigneau, A., Toniazzo, T., Minnis, P., Palikonda, R., Abel, S. J., Brown, W. O. J., Williams, S., Fochesatto, J., and Brioude, J.: The VAMOS Ocean-CloudAtmosphere-Land Study Regional Experiment (VOCALS-REx): goals, platforms, and field operations, Atmos. Chem. Phys. Discuss., 10, 20769-20822, doi:10.5194/acpd-10-20769-2010, 2010.

Wyant, M. C., Wood, R., Bretherton, C. S., Mechoso, C. R., Bacmeister, J., Balmaseda, M. A., Barrett, B., Codron, F., Earnshaw, P., Fast, J., Hannay, C., Kaiser, J. W., Kitagawa, H., Klein, S. A., Khler, M., Manganello, J., Pan, H.-L., Sun, F., Wang, S., and Wang, Y.: The PreVOCA experiment: modeling the lower troposphere in the Southeast Pacific, Atmos. Chem. Phys., 10, 4757-4774, doi:10.5194/acp-10-4757-2010, 2010.

Zängl, G.: An improved method for computing horizontal diffusion in a sigma-coordinate model and its application to simulations over mountainous topography, Mon. Weather Rev., 130, 14231432, 2002. 